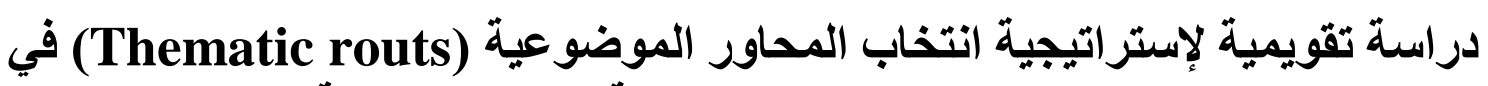
مشروع التجديد الحضري لمدينة الموصل القديمة

$$
\begin{aligned}
& \text { د. ناهض طه القيماقجي م. حاتم حازم الصوفي د. د. عماد هاني العلاف }
\end{aligned}
$$

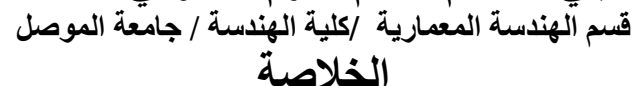

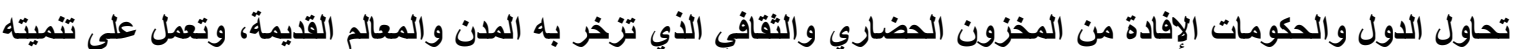

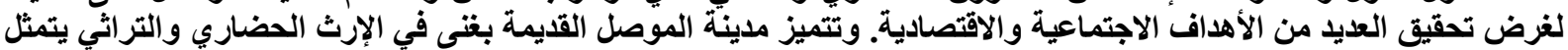

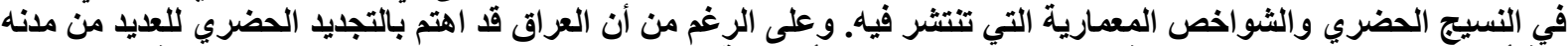

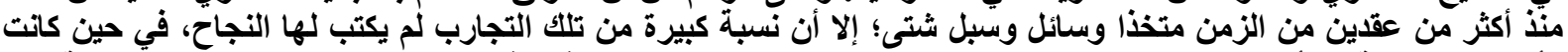

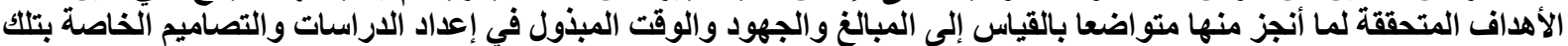

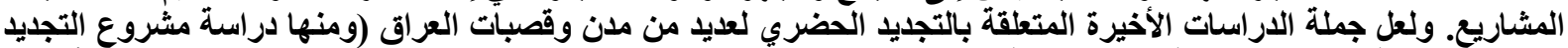

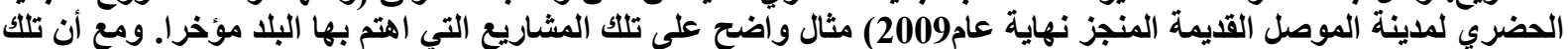

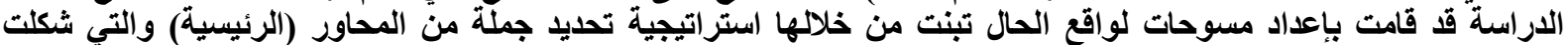

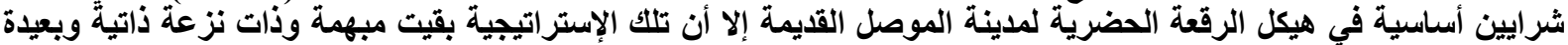

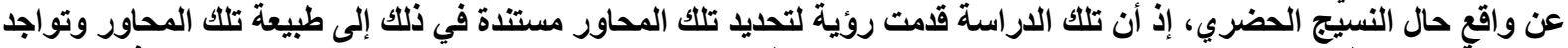

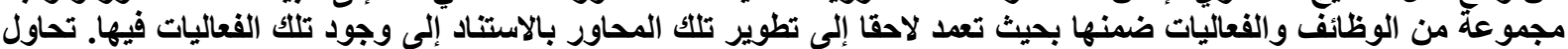

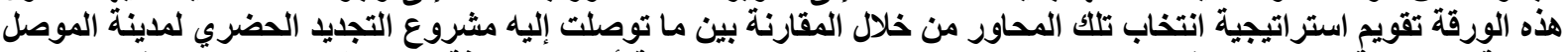

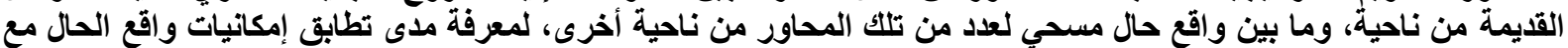

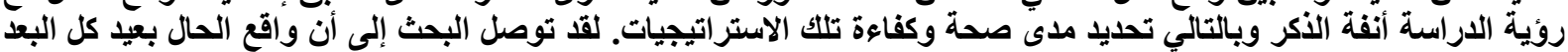

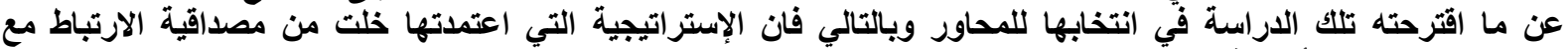
الإمكانيات التي يمكن أن يوفرها الموقع.

كلمات دلالة: الاستراتيجية التصميمية، استراتيجياته التجديد الحضري ،تقويم الاستراتيجيات، الحفاظ ، التراث العمراني ، مدينة الموصل القديمة

\title{
Evaluation Study of the Election Strategy of the Thematic Routes in the Urban Renewal Project for Mosul Old Town
}

\author{
Dr. N.T. Alkymakchy \\ H. H. Alsoofe \\ Dr. E. H. Alallaf
}

\begin{abstract}
Governments attempt to take advantage of cultural heritage that is rich in old cities, and work on its rehabilitation to achieve many goals well known to people who works in the urban renewal field. Like other Arabic Islamic cities, Mosul is characterized with its richness of cultural and spiritual heritage and all its alleys tell the story of building and their memories. The most recent studies on inter urban renewal for many cities in Iraq (including the project of urban renewal of the old city of Mosul, done at end of 2009) adopted by the General Directorate of Urban Planning, which has referred to a number of expert companies, is a clear example of that projects which the country took an interest in it recently. Although the project has prepared surveys of the case and has adopted strategy of identifying a set of thematic routes that formed essential arteries of the urban area of the old city of Mosul, but that strategy remained in many cases, vague and far from the reality of the urban space and its potentiality. This paper attempts to evaluate the strategy of the election of such routes carried out by that project through the findings of that study on one hand. In addition, between the reality of the surveying of a number of those routes on the other hand, to distinguish the compatibility of the real situation with the goals of that project and then the validity of those strategies. The results declare that the election of such routs is far away from actuality, so that it is true to announce that this strategy is invalid with in the corresponding of potentiality of the actual case of Mosul city.
\end{abstract}

Keywords: Design Strategy, Urban Renewal Strategy, Strategy Evaluation, Urban Conservation, Cultural Heritage, Old City of Mosul

$$
\text { قبل: } 2013 \text { - } 5 \text { - } 17
$$$$
\text { أستلم: } 2011 \text { - } 9 \text { - 27 } 27
$$ 
إن من الأهمية بمكان لأية در اسة علمية تحديد المرتكز ات الأساسية المعتمدة من قبلها في رسم الخط العام لتنالك الدر استة

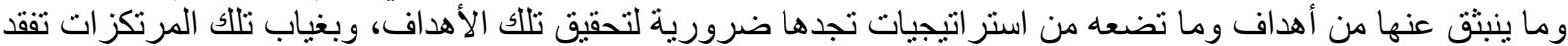

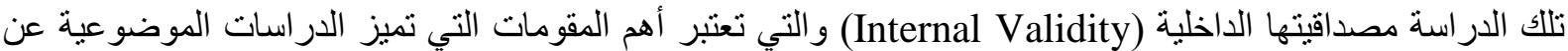

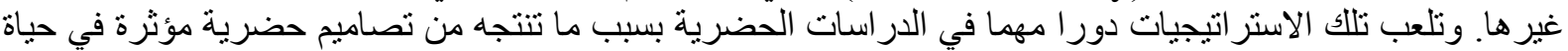

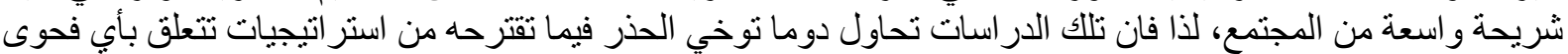

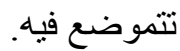

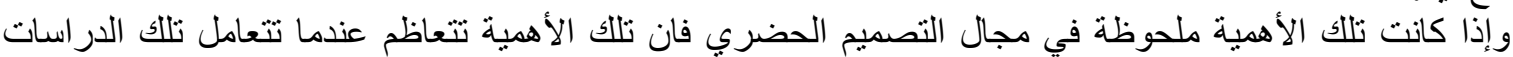

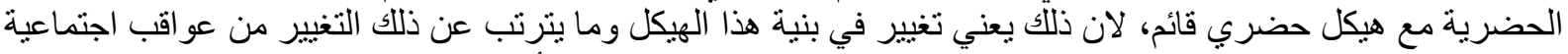

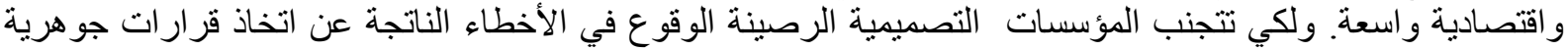

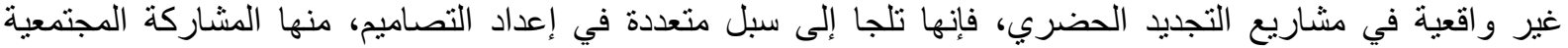

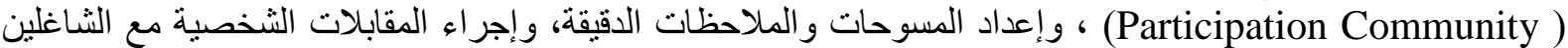

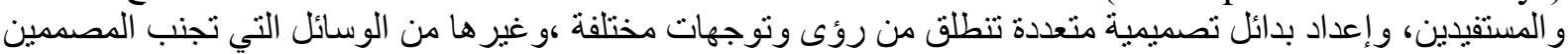

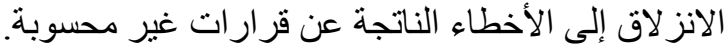

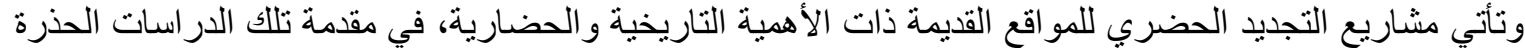

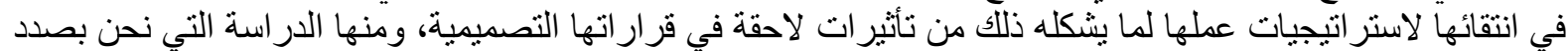

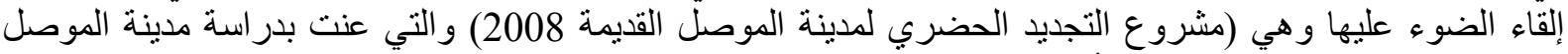

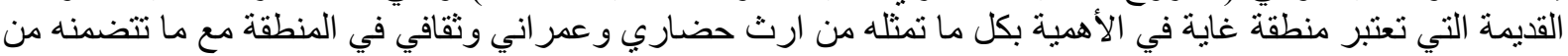
مشكلات اجتماعية و اقتصادية و عمر انية مركبة.

\section{1- 1 هدف الدر اسة ومنهجيتها:}

يتمحور البحث حول تقييم الاستر اتيجيات التي تم وضعها من قبل الجهة المصممة المعدة للمشروع و التي تم فيها

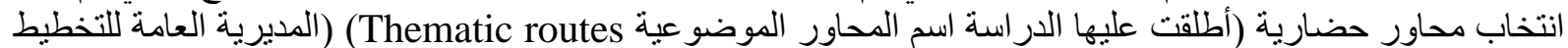
العمر اني، 2008، التقرير FF، 127) تركزت عليها عمليات التجديد الحضري التوري وإعادة التأهيل لمنطقة الدر اسة.

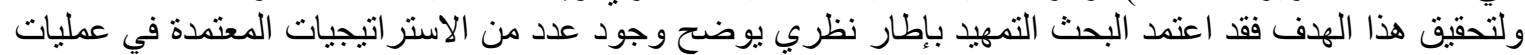

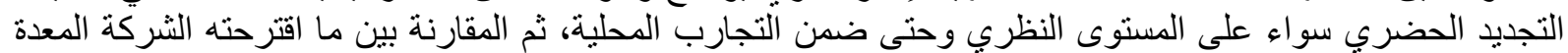

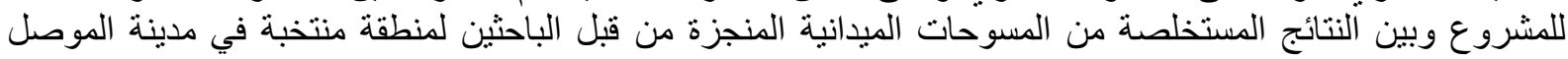

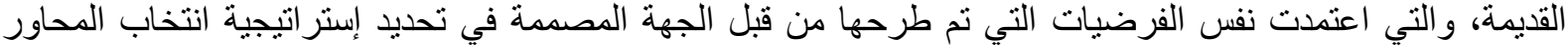
الحضرية(كما سيتم توضيحه لاحقا)، وذللك لغرض معرفة مدى تطابق تللك الخيار ات مع بعضها ومن ثم تحديد كفاءة تلك تلك الإستر اتيجية المقترحة.

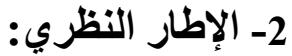

1-2 -2 استراتيجيات تحديد المسار المسارات في الاراسات الحضرية:

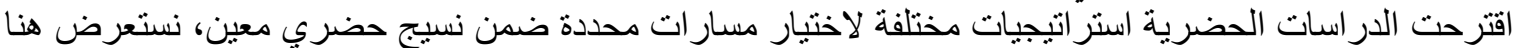

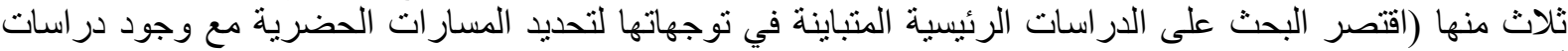
أخرى متعددة في هذا المجال):

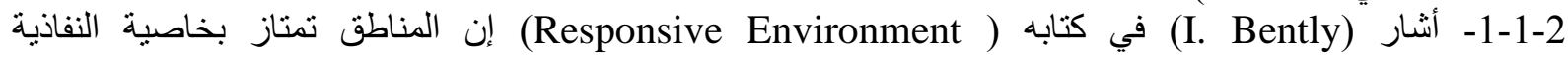
(Permeability)

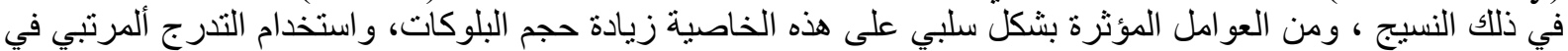

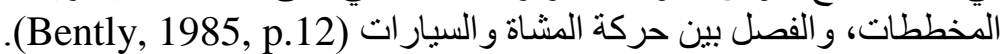

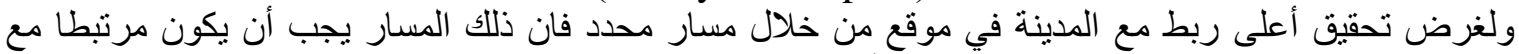

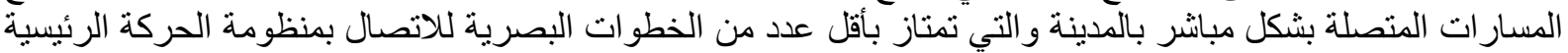

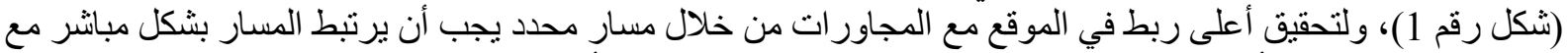

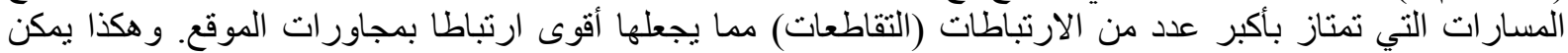

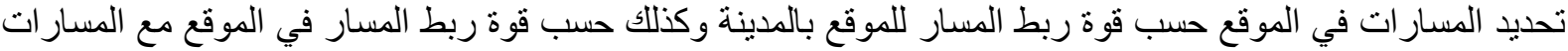

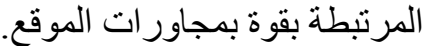
لقد ركزت دراسة (I. Bently) على منظومة النفاذية الحركية و البصرية في الهيكل الحضري كأحد المنظومات المهمة في تحديد المسار ات. وربطت تللك الوصولية بالمحورية الحركية لتلك المسار ات مما يزيد من قيمة المسارات التي التي 
يتم اختيار ها وبالتالي يزيد من درجة نفاذية الموقع. وهي بهذا تكون قد ربطت هيمنة مسار معين بطول وعرض ذلك المسار

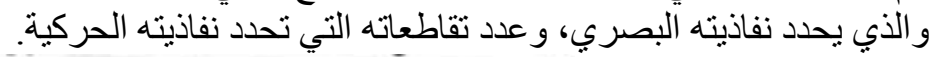

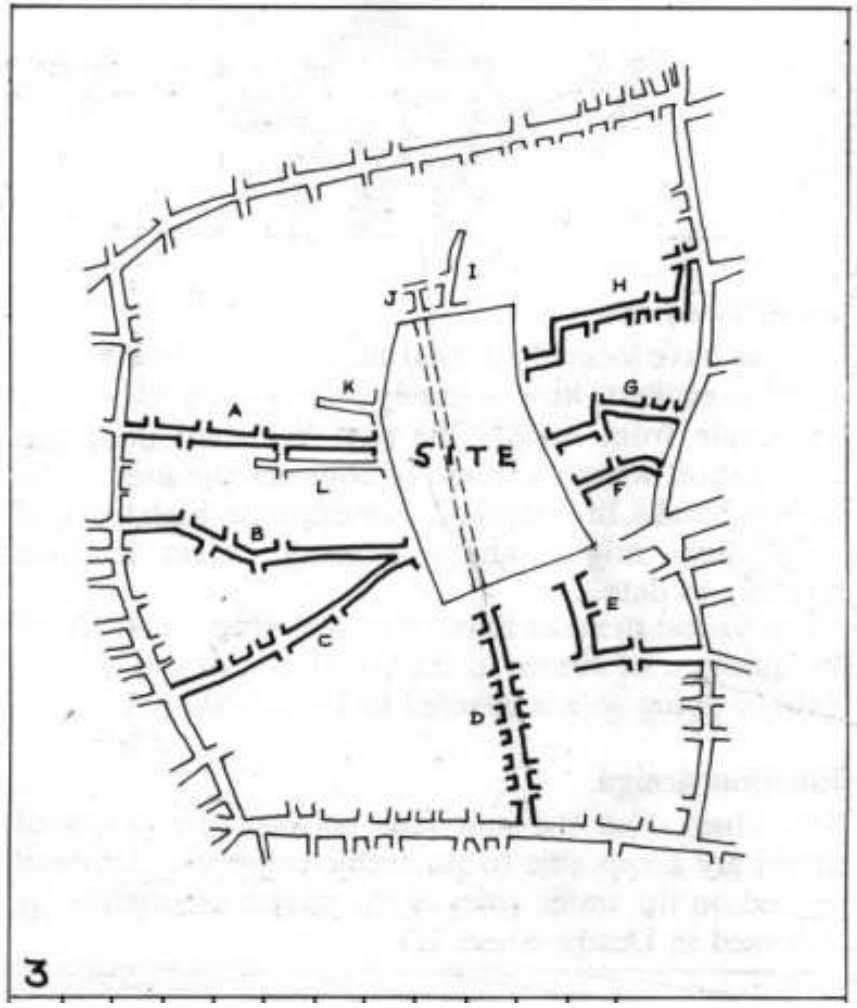

(Bently 1985, p. 16) (شكل رقم1) المسار في الموقع حسب قوة ربط المسار للموقع بمجاور اته بالمدينة

2-1-2- أما در اسة (B. Hillier) فقد ركزت على قو اعد تركيب الفضاء (Space Syntax)، إذ نثير خاصية التكامل في

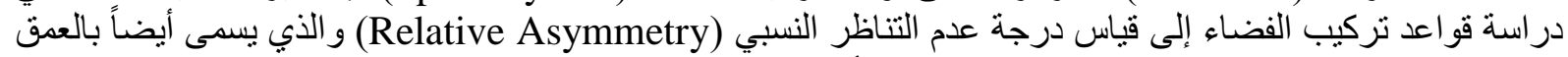

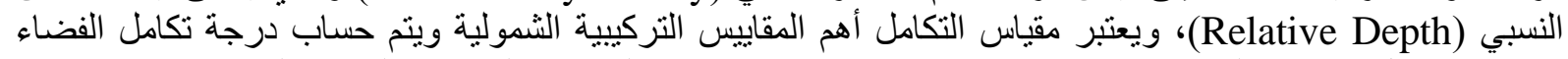

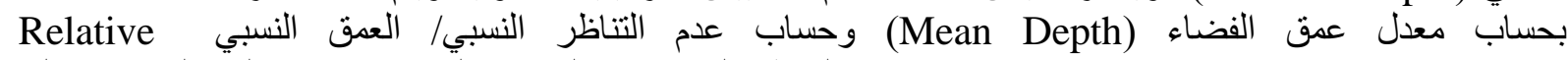

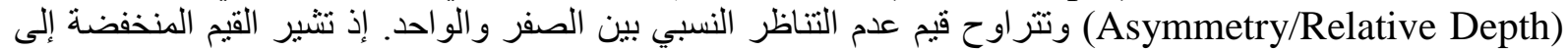

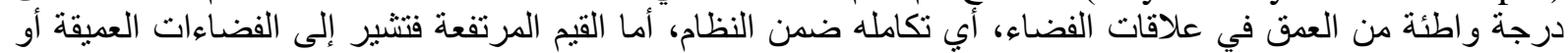

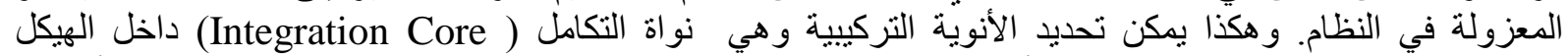

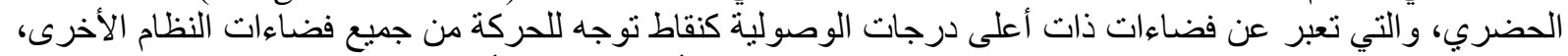

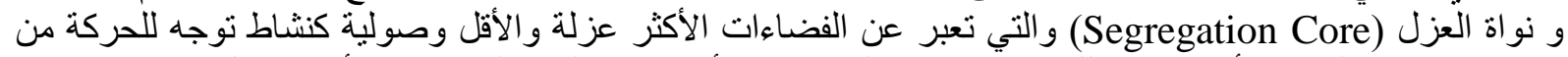

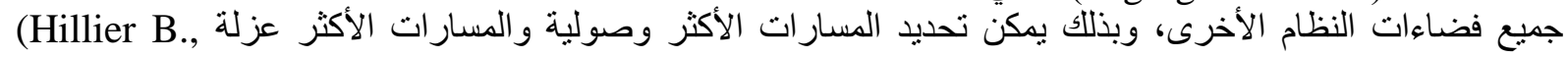
.(Hillier, 2002) Hanson, J.,1984), (Seamon D.,1994), (U1 Haq S., 2001),( Vaughan L., 2007) وكغير ها من الدر اسات التركيبية ، استند (B. Hillier) في دراسته على إستر اتيجية تعتمد الوصولية كمبدأ من أهم المبادئ التي يقوم عليها تكامل الفضاء الحضر التري.

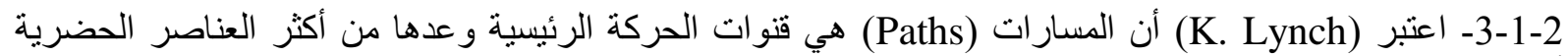

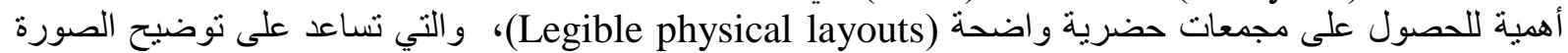

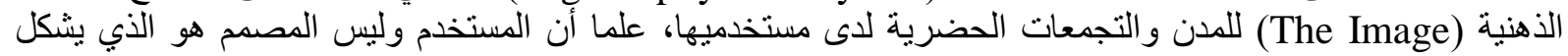

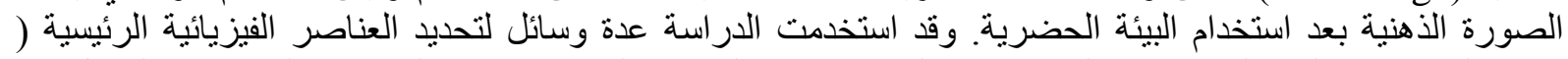

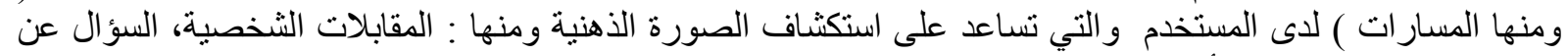

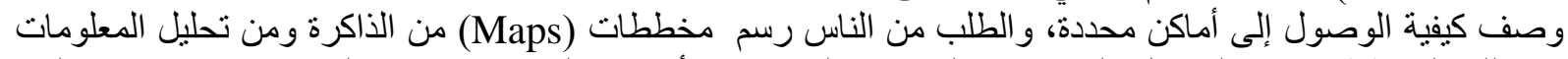

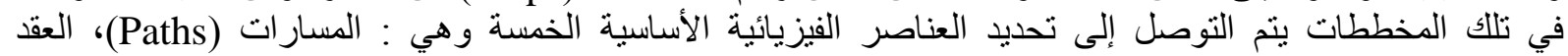
(Nodes))، الحافات (Edges)، نقاط الدلالة (Landmarks)، المناطق القطاعية (Districts) (شكل رقم 2). وبذللك يمكن 
تحديد المسار ات المهمة والو اضحة في البيئة الحضرية من وجهة نظر مستخدمي البيئة وشاغلي المكان وليس حسب وجهة نظر المصمم فقط (Lynch,1960,p. 15). نُوندارل

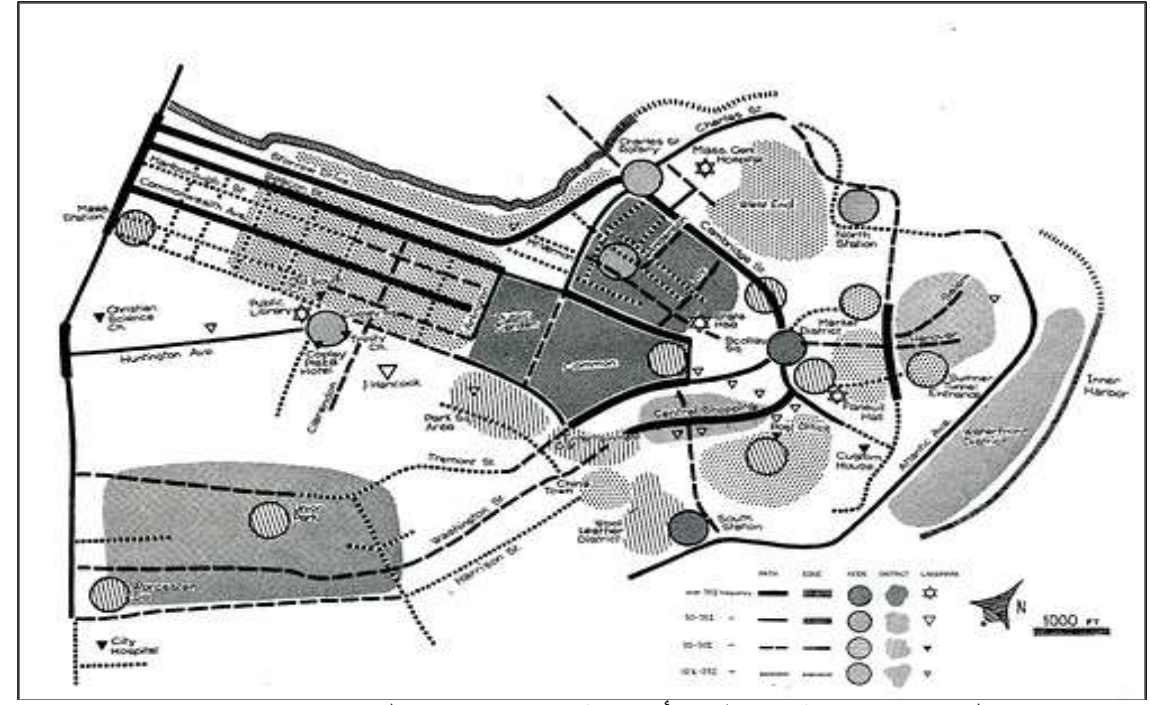

(شكل رقم 2) مدينة بوسطن الأمريكية حسب عناصر لنج (Lynch, 1960)

يمكن الإشارة الى دراسة (K. Lynch) باعتبار ها الدراسة الرائدة في تحديد محاور المناطق العمرانية بحسب

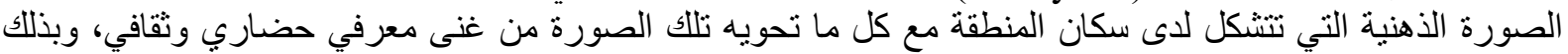

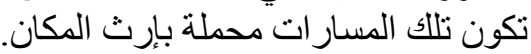

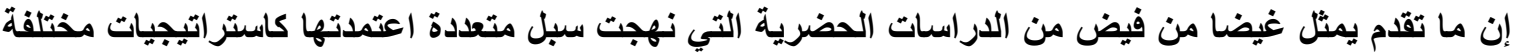

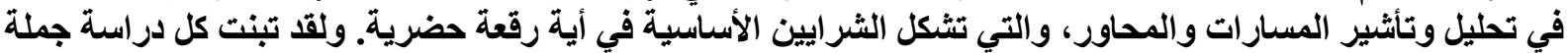

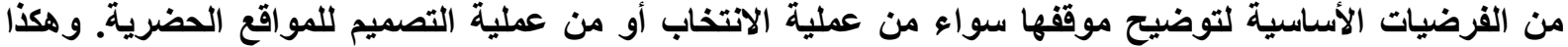

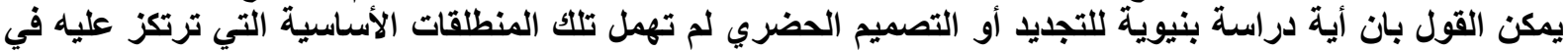

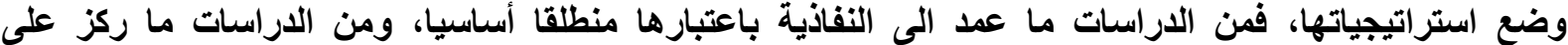

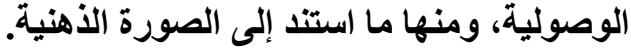

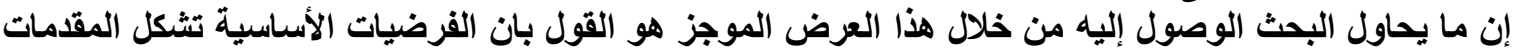

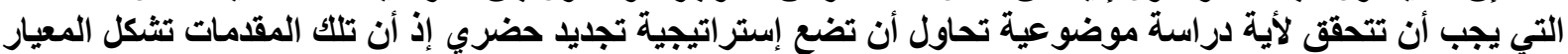

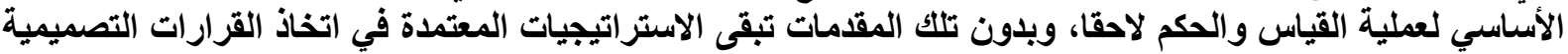

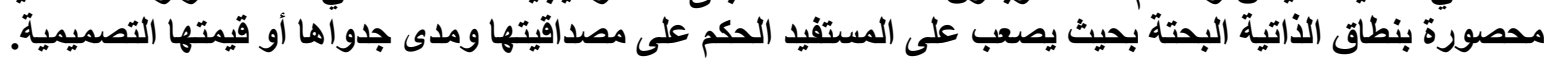

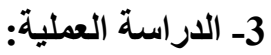

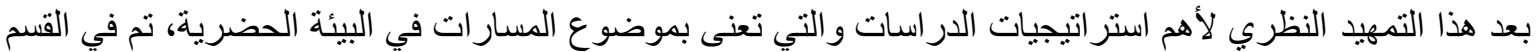

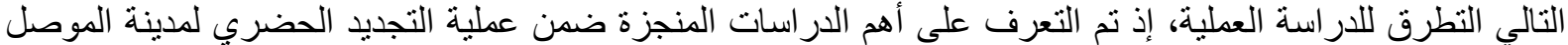

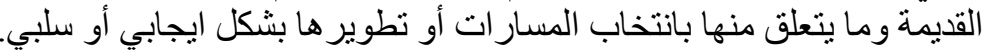

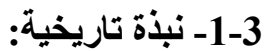
تعد مدينة الموصل القديمة من المدن العر اقية الغنية بتاريخها الحضاري، فهي وريثة نينوى عاصمة الآشوريين وذات الآئ

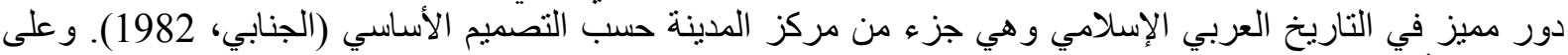

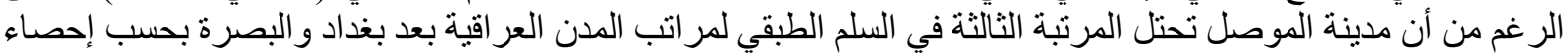

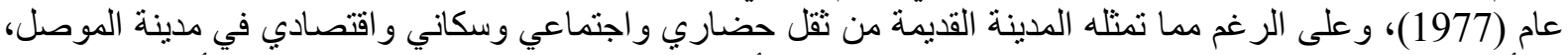

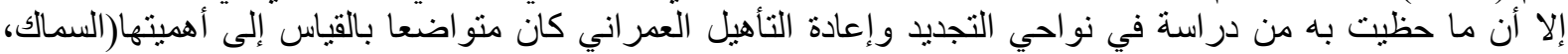

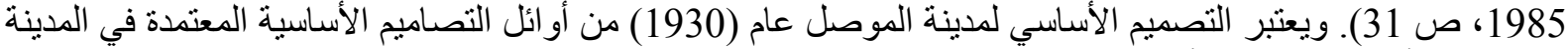

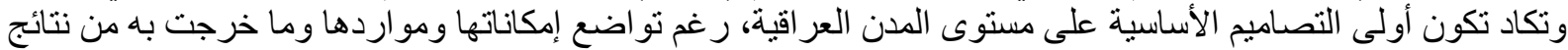

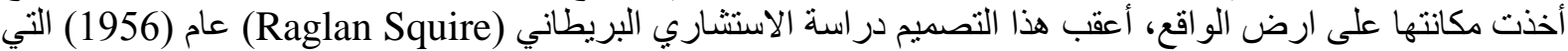

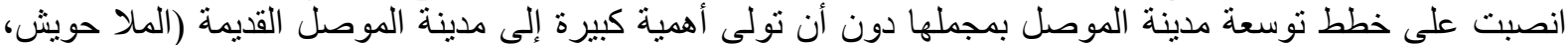
1988، ص 32)، إذ كان القصد منها عزل مدينة نينوى الأثرية عن باقي أجز أولئ كيرة المدينة. 
وفي هذا السياق يمكن أن نذكر ثلاثة من الدراسات التي كان لها ثقلها التصميمي و التي أعدت ضمن مجال التجديد الحضري

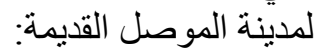

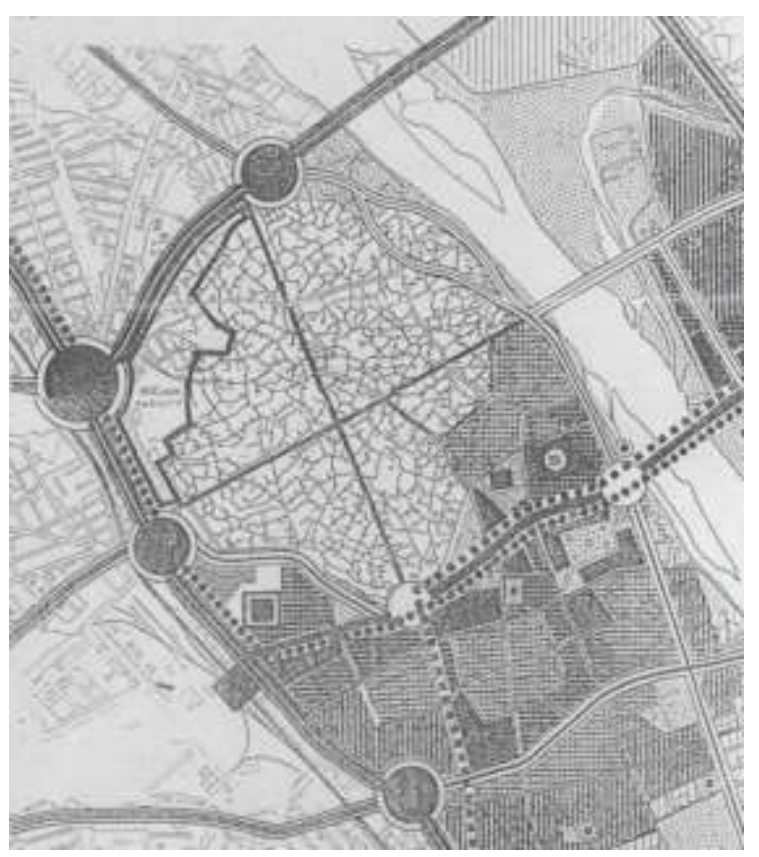

1-3-3 التصميم الأساسي لمدينة الموصل 1978. قامت شركة سيت انترناشيونال الفرنسية بالاشترالك مع الكع مكتب دار العمارة العراقي بوضع تصنيم تصميم أساسي لمدينة

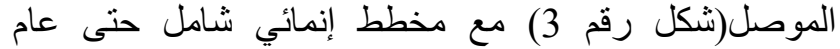

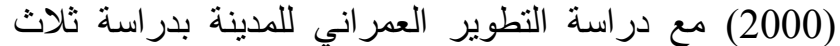

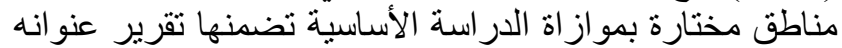
المناطق المختارة (Selected Areas) وهي (إبر اهيم، 1989

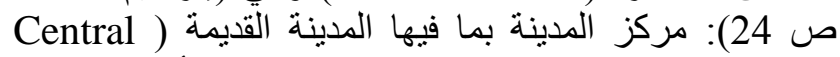
(Area)، منطقة المدينة القديمة (Old City) و أخير المناطق (Ctea الحفاظ (Conservation Areas).

و على الرغم من أن التصميم ارتكز في استراتيجياته لتطوير

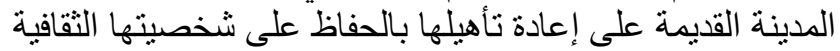

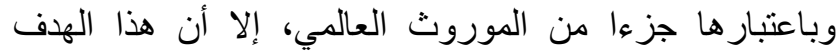

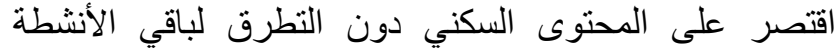
والفعاليات هذا من ناحية، ومن ناحية أخرى فأن التصميم الأنيمية

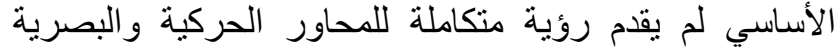
للمدينة القديمة بقدر ما ركز على مناطق معينة ضمن الإنة المدينة

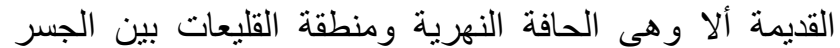

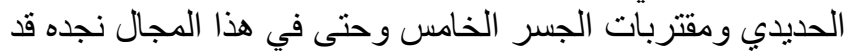

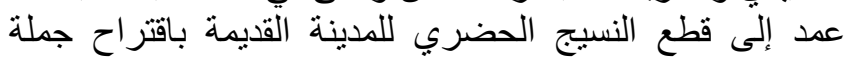

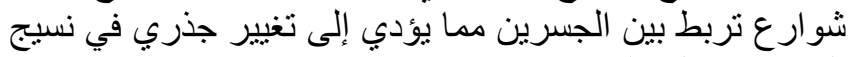

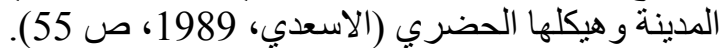

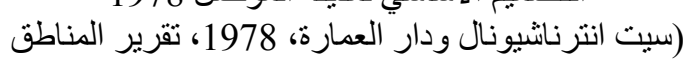

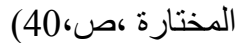

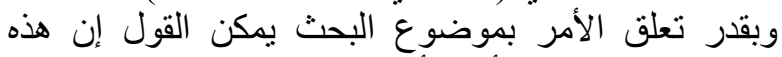

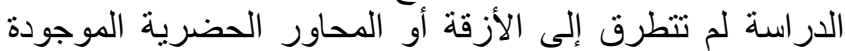
ضمن نسيج المدينة القديمة باقتر احات عملية تتعلق بعملية تجديدها أو إعادة هيكلتها وذلك انطلاقا من إستر اتيجية الحفاظ

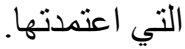

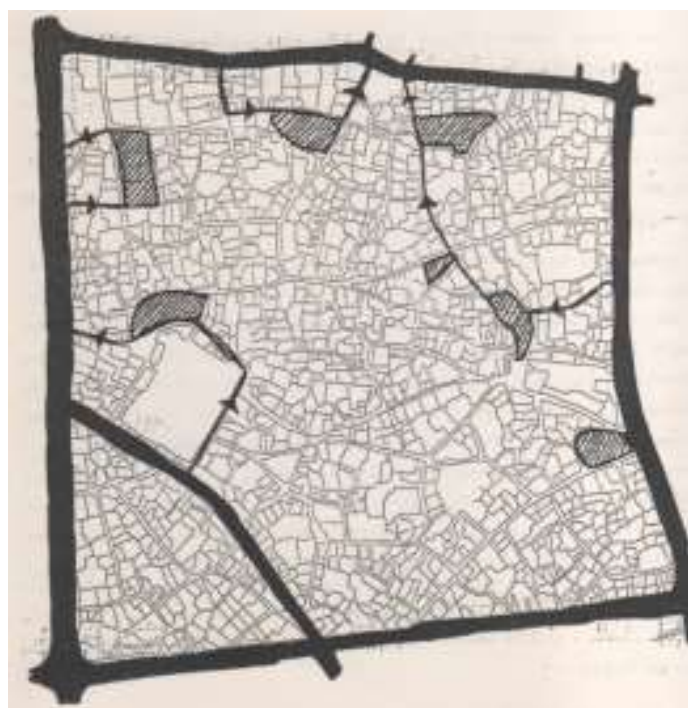

2-1-3 دراسة وحدة التخطيط العمراني 1988. نتيجة لجملة من المعوقات فان المدان المخطط الأساسي لمدينة

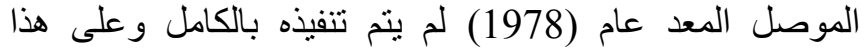
الأساس فقد قامت وحدة التخطيط العمراني في الموصل بإن بإعداد

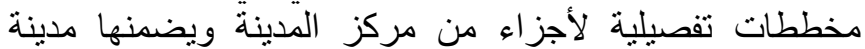
الموصل القديمة عام (1988)، ارتكزت في في معظمها لفئ على أساس

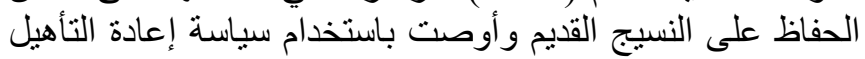

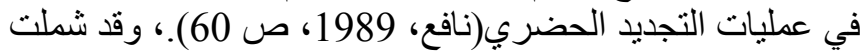

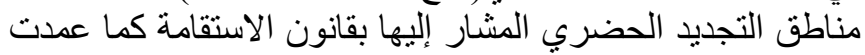

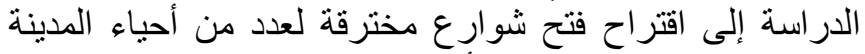

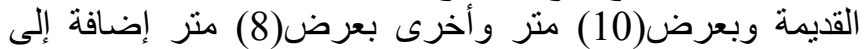
اقتراح الدراسة استغلال المناطق المتهرئة من الفرئة النسيج الحضري

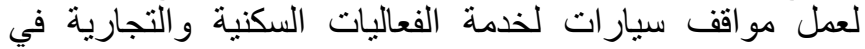
المنطقة (شكل رقم 4).

(شكل رقم 4) نموذج من الثو ارع المخترقة ومو اقف السيار ات في مقترحات

التجديد الحضري لمدينة الموصل القديمة المعد من قبل وحدة التخطيط

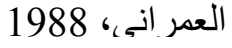


و ولى الرغم من تو اضع الدر اسة ومحدودية البيانات التي اعتمدتها، فان سياسة الحفاظ التي اقترحتها كانت مو فقة في

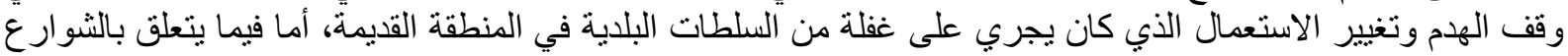

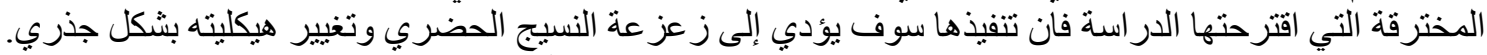

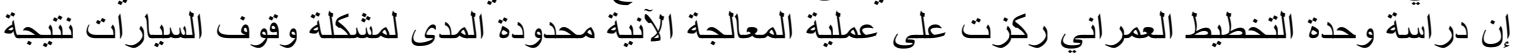

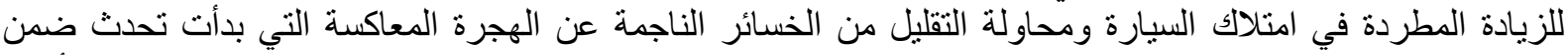

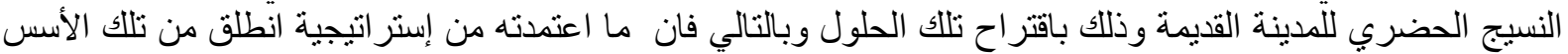

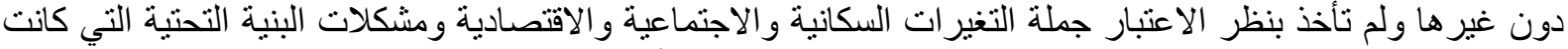

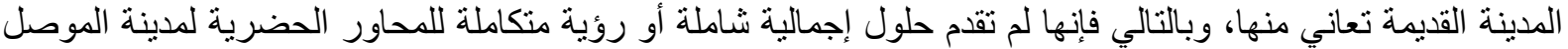

إن ما تقدم يشير إلى وجود عدد من المحاولات على المستوى المحلي والتي حاولت أن تقدم رؤى متباينة للنسيج

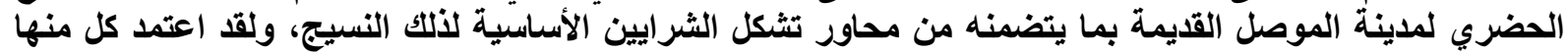

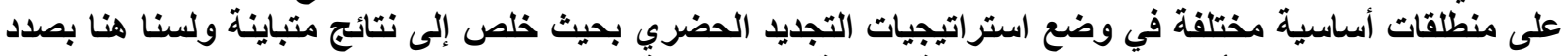

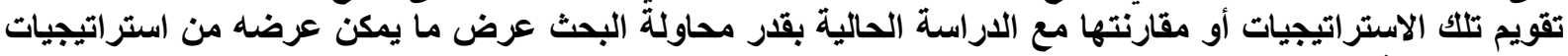

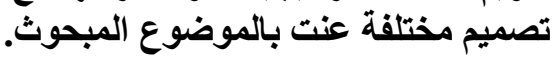

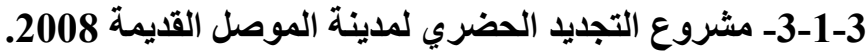

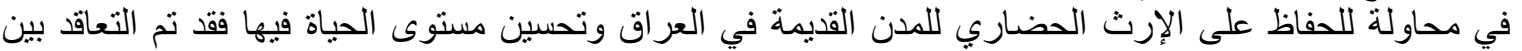

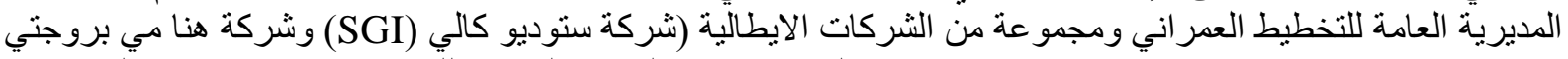
(HANAmi)

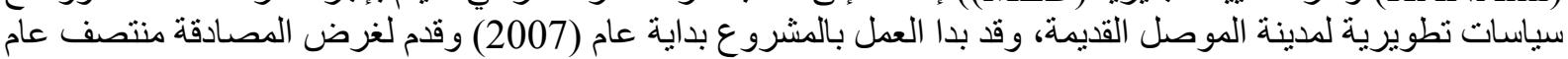

لقد تم تقديم وثائق الدراسة مع توصياتها في ستة مجلدات تضمنت المسوحات الميدانية وتحليل تلك المكات المسوحات وسيناريو هات العمل إضافة إلى وثائق المقترحات و ألتوصيات وخطة التطوير (شكل رقم 5).

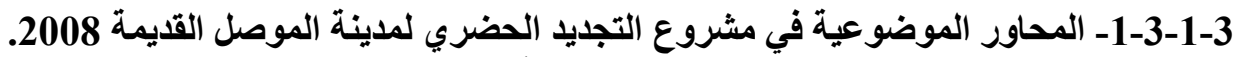

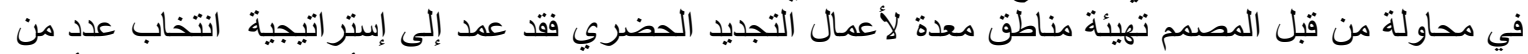

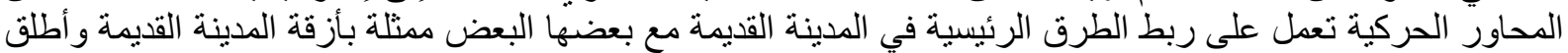

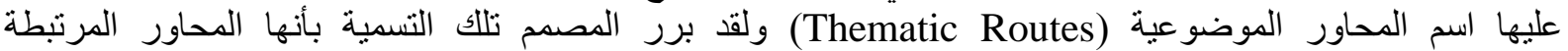

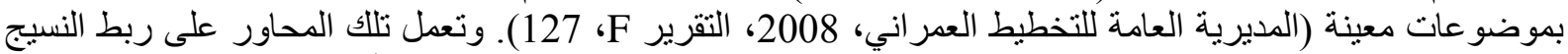

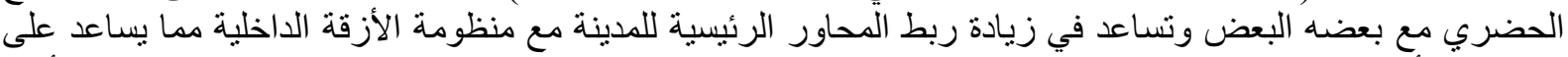

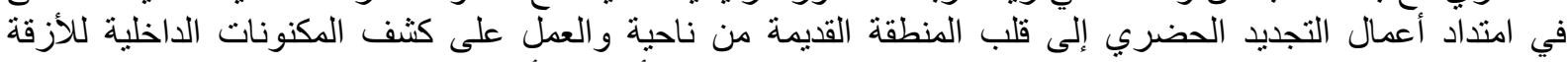

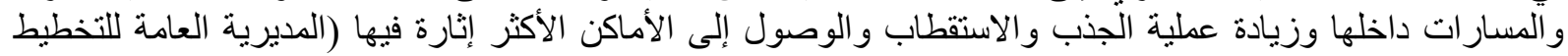

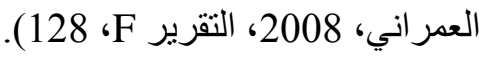

2-3-1-3- فرضيات مشروع التجديد الحضري لمدينة الموصل القديمة 2008.

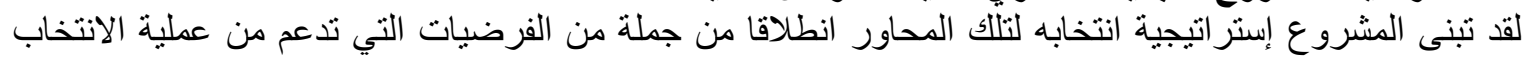

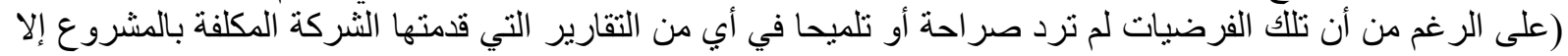

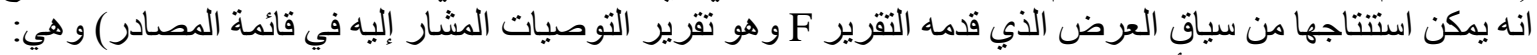

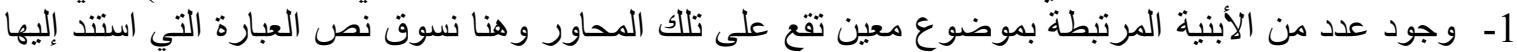

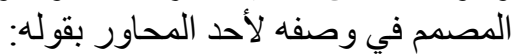

" باستطاعة المريء تخيل وجود طريق روحي بتألف من طرق ضبقة ويفضي إلى الأماكن الدينية العدبية من جوامع

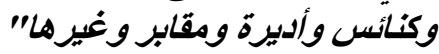

2- أهمية تلك المحاور من ناحية عرضها وموقعها من التسلسل الهرمي للأزفة فيرة في قلب المدينة القديمة ودور ها في

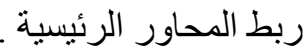

3- نمط وطبيعة الاستعمال المييمن على نلائك المحاور والذي يحدد طبيعتها وموقعها في الذاكرة الاجتماعية لسكان

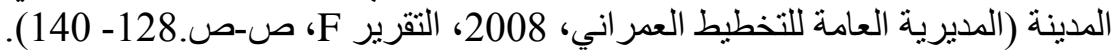




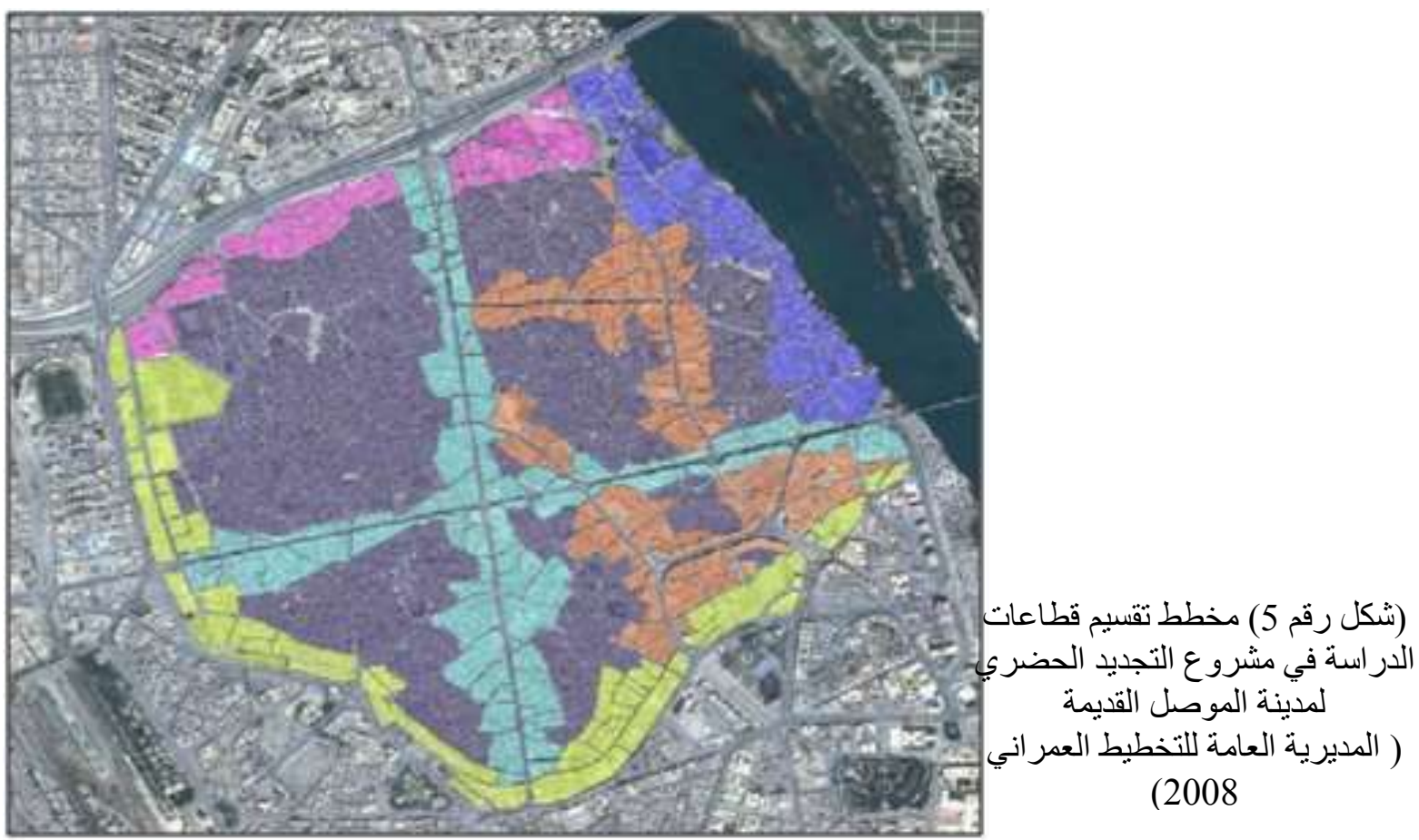

إن تلك الفرضيات قادت دراسة مشروع التجديد الحضري لمدينة الموصل القديمة إلى تبني إستراتيجية تحديد ثلاثة

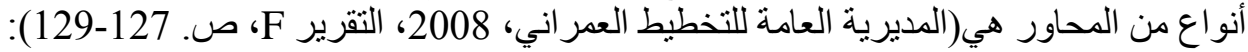
1- المحاور الروحية (Spiritual Routs) باحتو ائها على جملة من المعالم الروحية كالجوامع و الكنائس والمراقد و المقابر (انظر ملحق رقم 1) (الرودة). 2- المحاور الثقافية (Cultural Routs) باحتو ائها على جملة من المعالم الثقافية كالمدارس والمتاحف و المكتبات

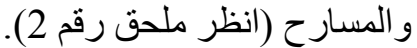

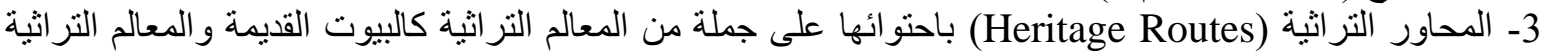
التي تزخر بها المنطقة كالقناطر ومتاجر الحرف اليدوية (انظر ملحق رقم 3ن 3).

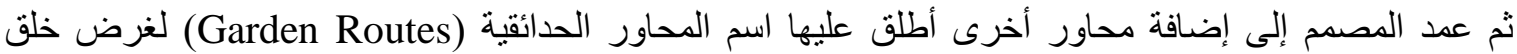

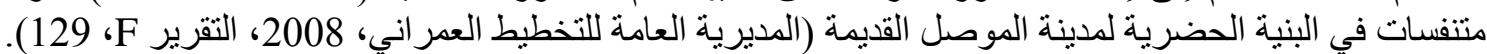

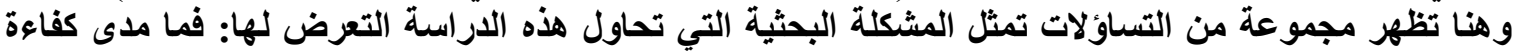

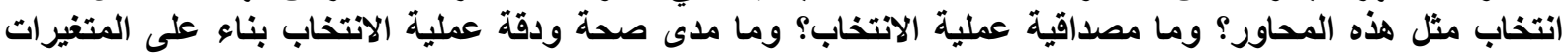

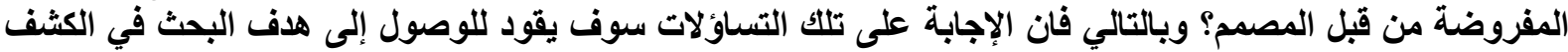

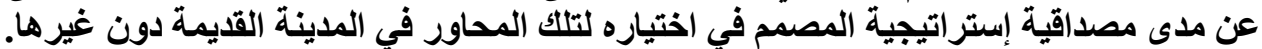

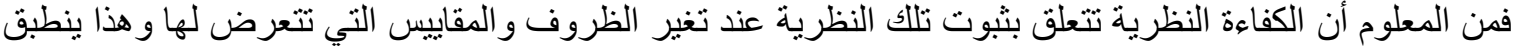
على الطرح الاستر اتيجي فان مصداقيته مرتبطة بثبوته أمام التغير في ظروف النئ القياس.

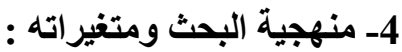
لتحقيق هدف البحث فقد نم انتخاب منطقة محددة في المدينة القديمة (لا تتمكن هذه الورقة البحت البحثية من تغطية المدينة

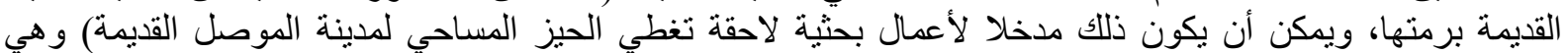

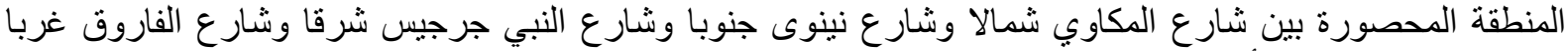

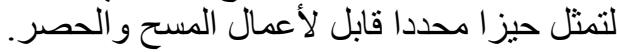
إن البحث لم يقم بانتخاب إحدى الاستر اتيجيات التي تبنتها الدراسات النظرية في هذا المجال واسقاطها النيا على السياق

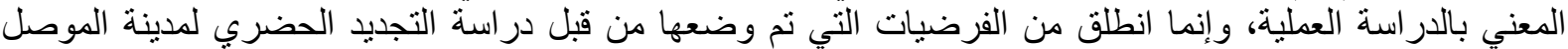
القديمة في تحديدها للأسس المعنمدة في تشخيص المحاور الموضو عية ( Thematic Routs) (المذكورة آنفا) ولكنها وفي نفس الوقت فقد اعتمد جملة من المقاييس الموضوعية التي تعبر عن تللك الفرضيات باعتبار انها إذا حدث تطأ تطابق بين المحاور المؤشرة من عملية القياس مع المحاور التي شخصنتها الدراسة فان ذلك سوف يقود إلى القول بكفاءة الدراسة في 


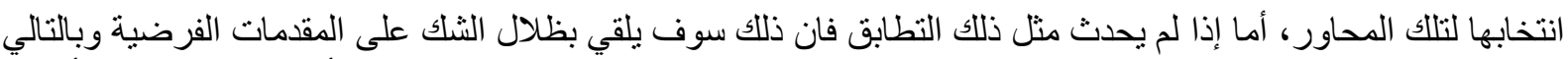

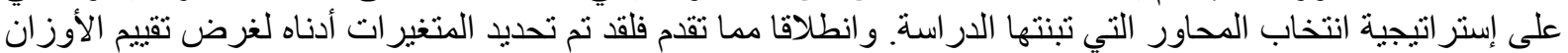

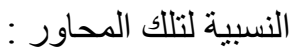

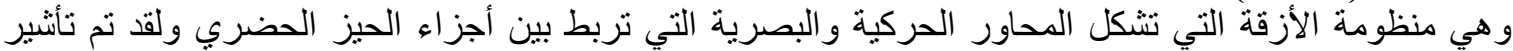

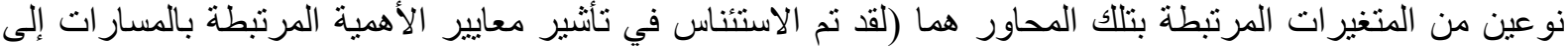

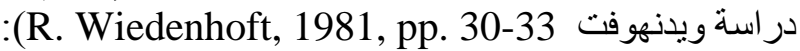

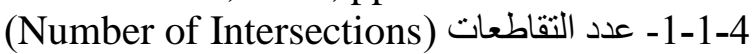

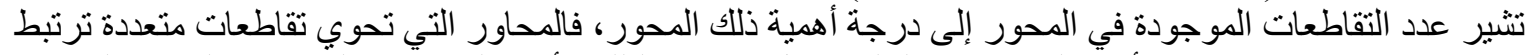

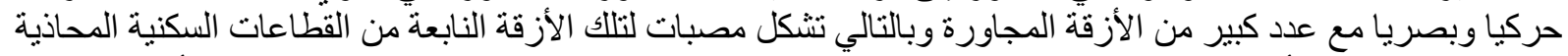

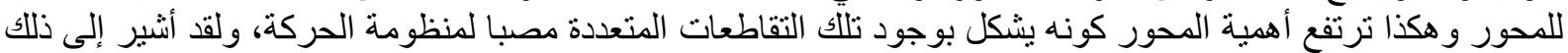

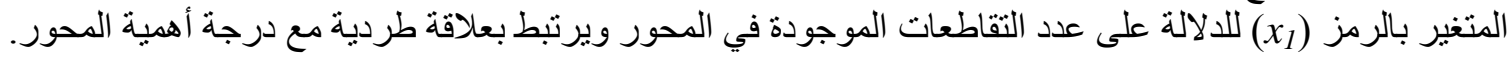

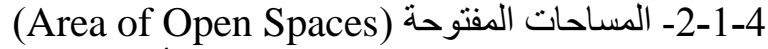

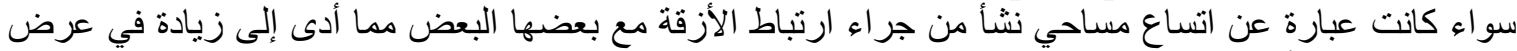

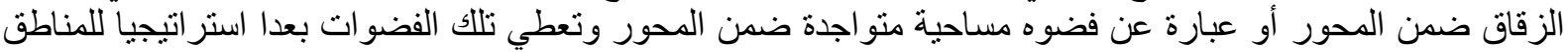

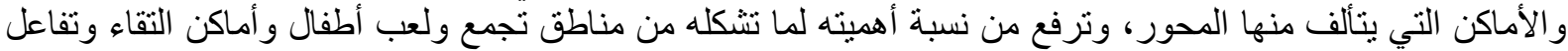

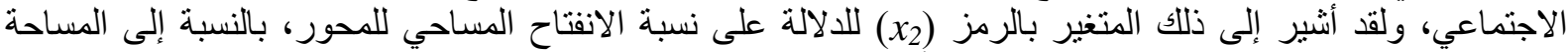

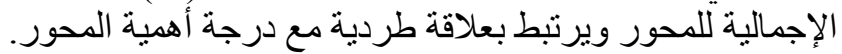

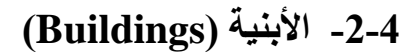

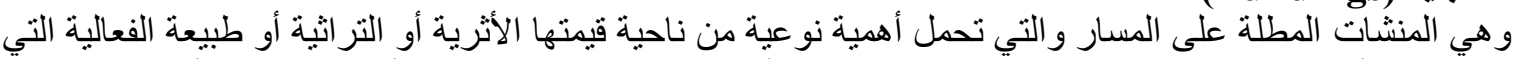

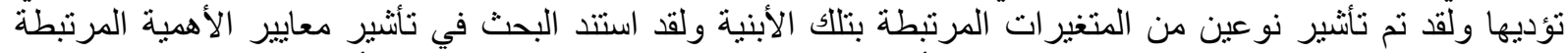

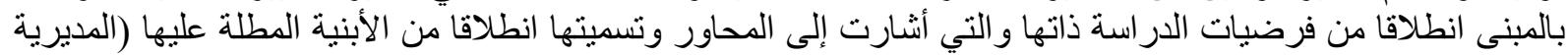

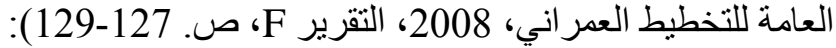

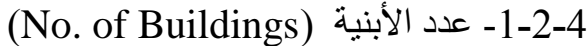

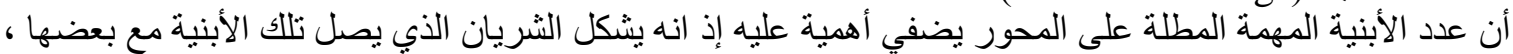

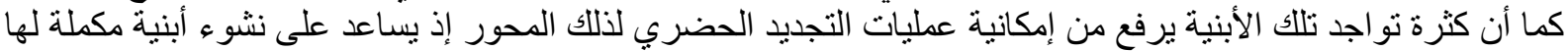

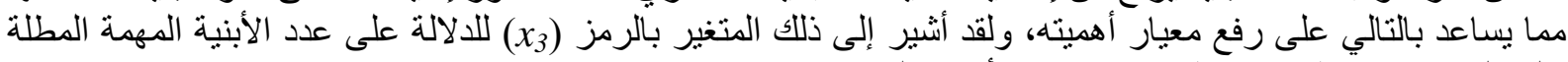

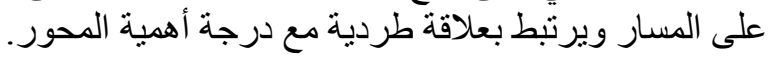

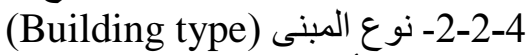

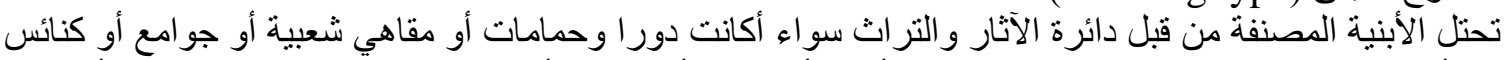

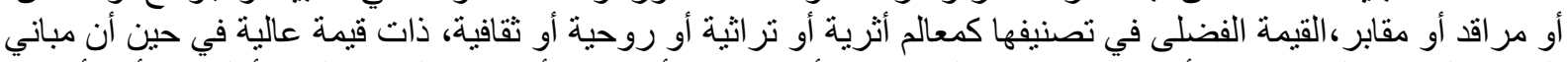

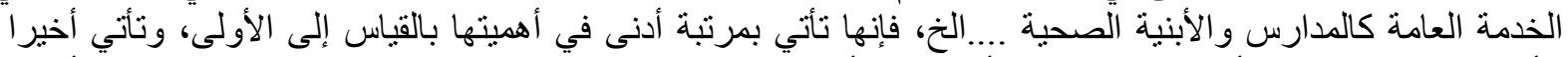

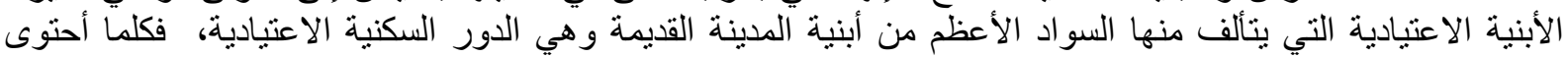

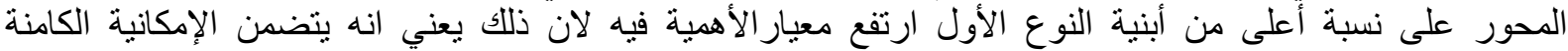

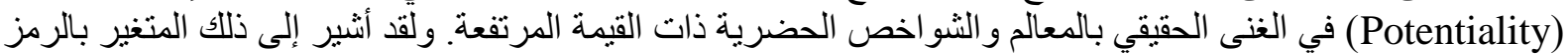

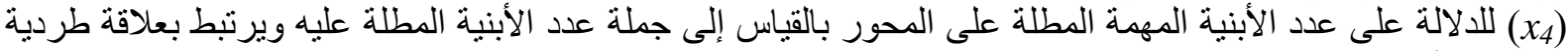

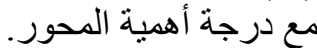
-3-2-4 - نسبة مساحة الاستعمال

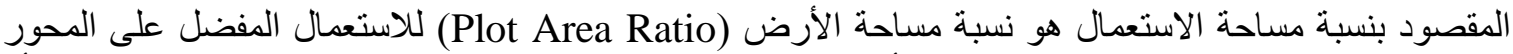

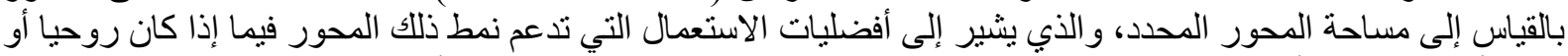

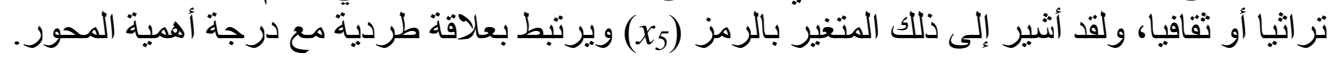

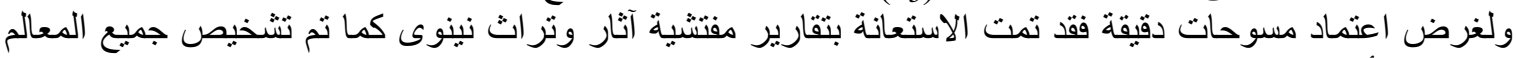

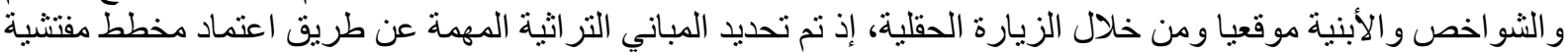

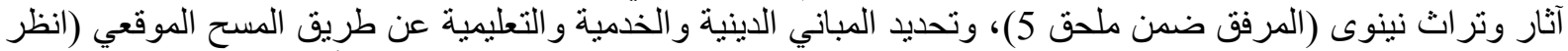

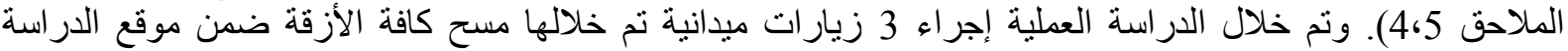

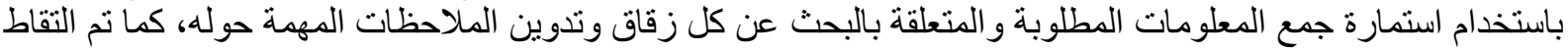


صور متسلسلة لكل زقاق (بمجموع أكثر من 850 صورة للمنطقة، و الملحق 4 يوضح جانبا من هذه الصور ) وباستخدام

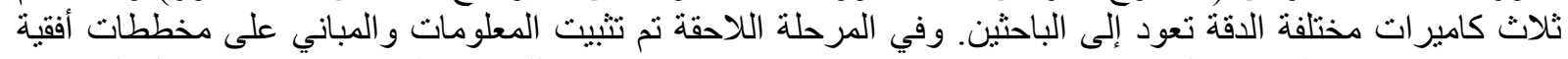

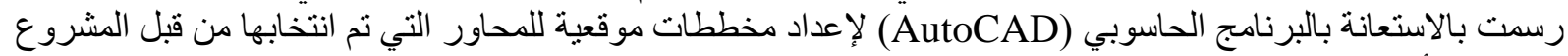

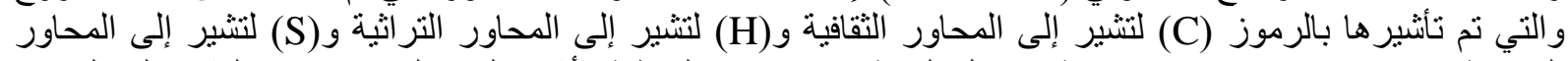

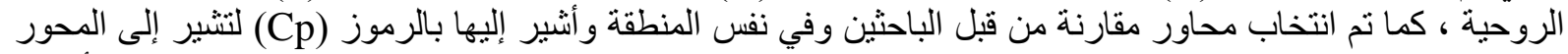

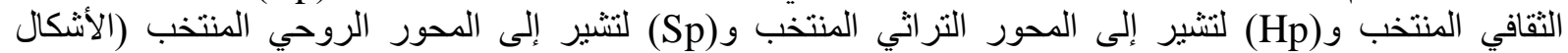

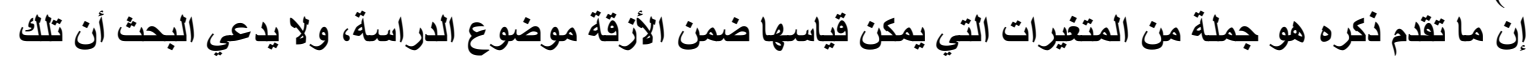

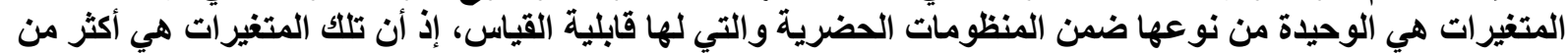

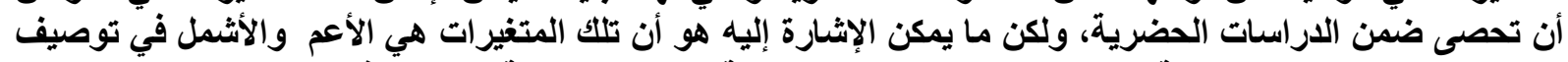

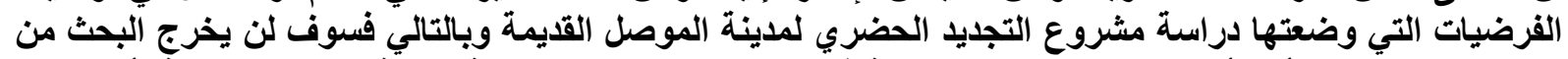

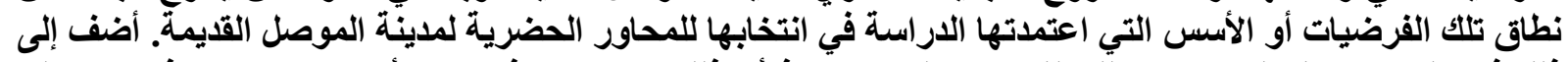

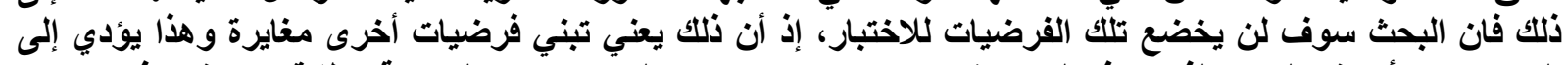

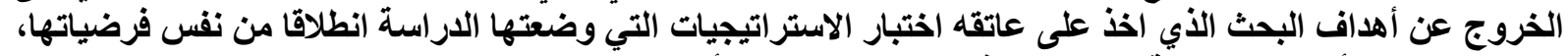

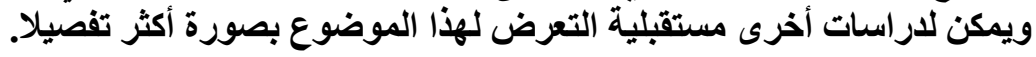

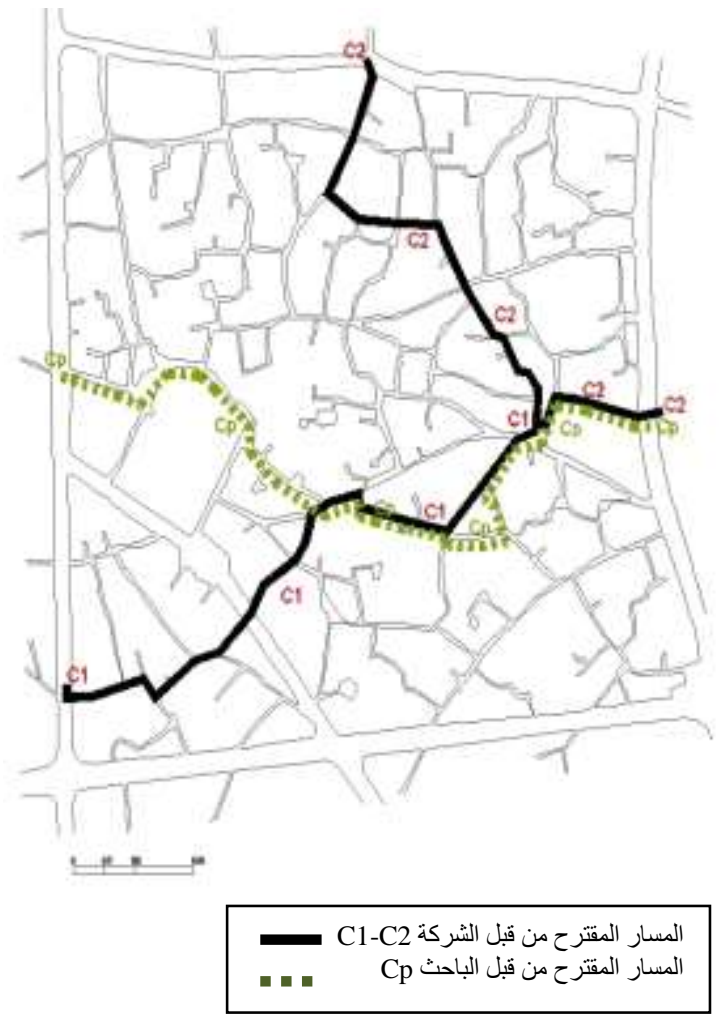

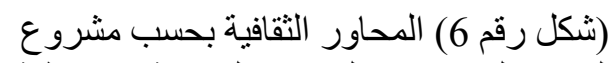
التجديد الحضري و المارحاور المنتخبة في منطقة الدراسة (المصدر: الباحث)

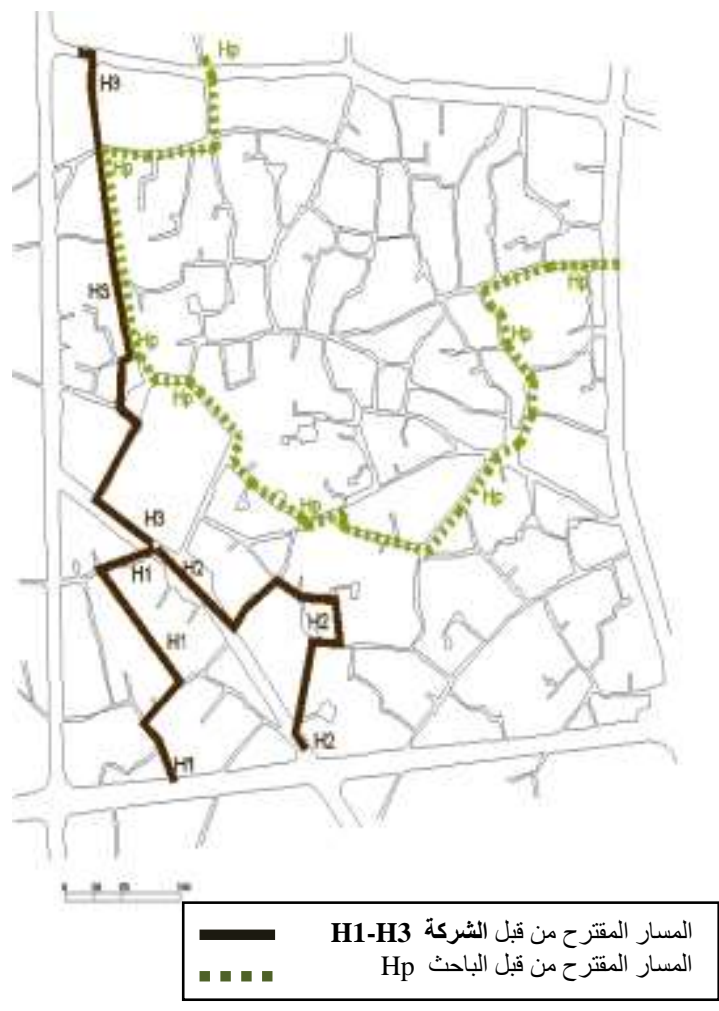

(شكل رقم 7) المحاور التراثية بحسب مشروع

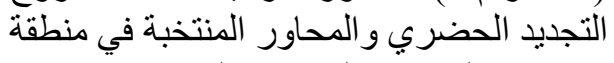
الدر اسة (المصدر : الباحث) 

No. 3
April 2014

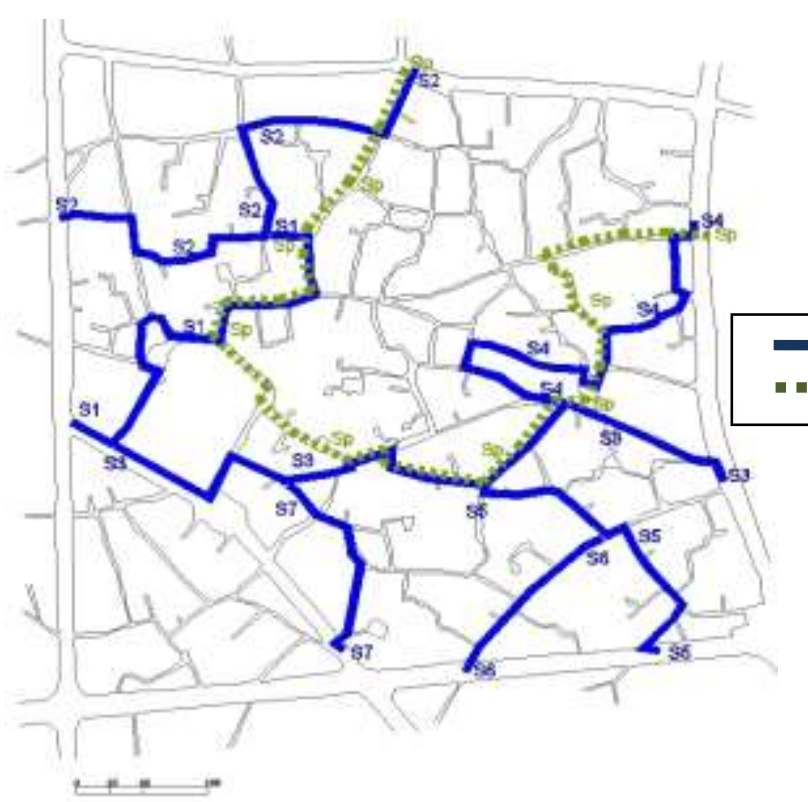

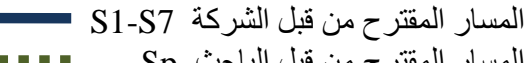

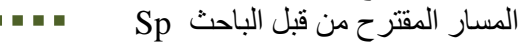

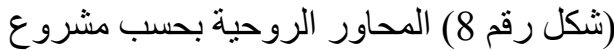

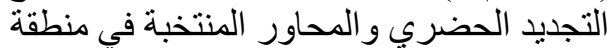

الدر اسة (المصدر: الباحث)

لقد اعتمد البحث أسلوب الحصر والته والترقيم في قياس المتغيرات أنفة الذكر إذ تم حصر الأبنية المطلة على المحاور كلا

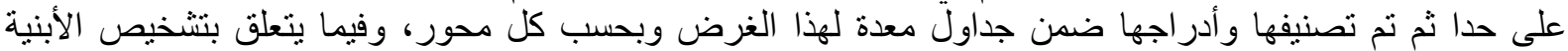

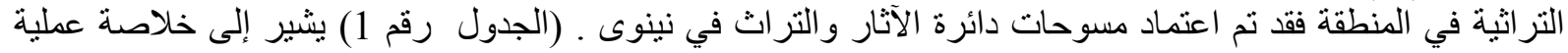

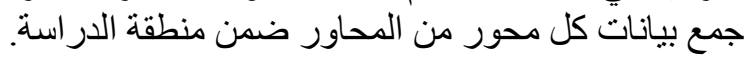

(جدول رقم 1) يوضح خلاصة قياس المتغير ات في المحاور (المصدر : الباحث) X3

\begin{tabular}{|c|c|c|c|c|c|c|c|c|c|c|c|}
\hline \multicolumn{3}{|c|}{ X5 } & \multicolumn{3}{|c|}{$\mathrm{X4}$} & X3 & \multicolumn{3}{|c|}{$\mathrm{X} 2$} & X1 & \\
\hline النسبة & 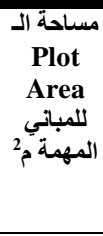 & اللمحور مُ المسالية & المجموع & الألعابنية & 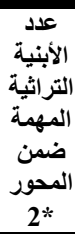 & المابنمية & المالنسبة بينة & 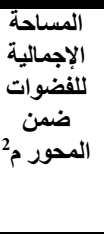 & 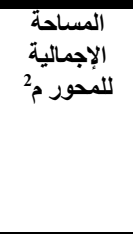 & التقاطعات & المحور \\
\hline 1.260 & 2015 & 1598.53 & 5 & 1 & 2 & 3 & 0.047 & 75 & 1598.53 & 15 & C1 \\
\hline 2.438 & 3372 & 1383.53 & 2 & 2 & 0 & 2 & 0.146 & 202 & 1383.53 & 17 & C2 \\
\hline 4.125 & 11056 & 2680.38 & 8 & 2 & 3 & 5 & 0.141 & 380 & 2680.38 & 17 & Cp \\
\hline & & & & & & & & & & & \\
\hline 0 & 0 & 765.55 & 0 & 0 & 0 & 0 & 0.066 & 51 & 765.55 & 7 & H1 \\
\hline 0.268 & 355 & 1322.68 & 3 & 1 & 1 & 2 & 0.074 & 98 & 1322.68 & 8 & H2 \\
\hline 3.917 & 7733 & 1974.73 & 6 & 2 & 2 & 4 & 0.071 & 142 & 1974.73 & 8 & H3 \\
\hline 3.677 & 13122 & 3568.55 & 39 & 3 & 18 & 21 & 0.129 & 462 & 3568.55 & 28 & Нр \\
\hline & & & & & & & & & & & \\
\hline 4.211 & 7421 & 1762.28 & 7 & 1 & 3 & 4 & 0.086 & 152 & 1762.28 & 12 & S1 \\
\hline 1.041 & 1675 & 1608.70 & 6 & 2 & 2 & 4 & 0.092 & 149 & 1608.70 & 11 & S2 \\
\hline 0.724 & 1456 & 2011.01 & 5 & 1 & 2 & 3 & 0.067 & 135 & 2011.01 & 15 & S3 \\
\hline 2.219 & 3272 & 1474.56 & 2 & 2 & 0 & 2 & 0.109 & 162 & 1474.56 & 10 & S4 \\
\hline 1.351 & 665 & 492.93 & 3 & 1 & 1 & 2 & 0.195 & 96 & 492.93 & 11 & S5 \\
\hline 0.264 & 83 & 314.35 & 2 & 0 & 1 & 1 & 0.115 & 36 & 314.35 & 5 & S6 \\
\hline 0.576 & 355 & 616.75 & 3 & 1 & 1 & 2 & 0.097 & 60 & 616.75 & 4 & S7 \\
\hline 3.560 & 12148 & 3412.45 & 14 & 0 & 7 & 7 & 0.148 & 505 & 3412.45 & 25 & Sp \\
\hline
\end{tabular}

(ملاحظة: يشير الصفر في الجدول الى عدم ظهور المتغير المشار اليه ضمن المسار) 


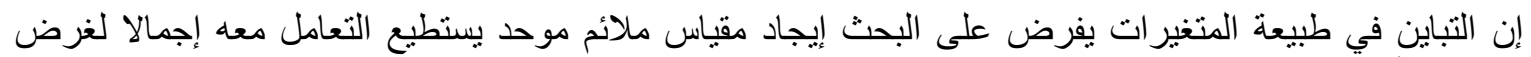

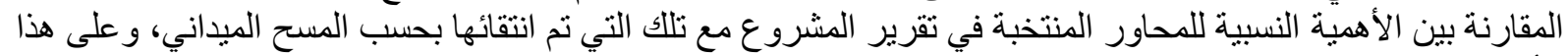

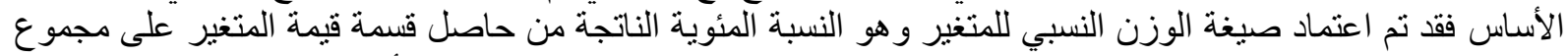

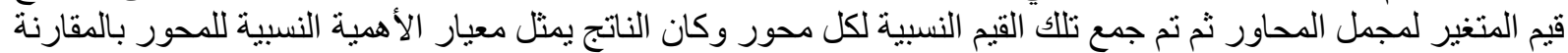
مع بقية المحاور ، وكما في النموذج التنالي.

$$
N=\frac{x 1}{\sum x 1} \%+\frac{x 2}{\sum x 2} \%+\frac{x 3}{\sum x 3} \%+\frac{x 4}{\sum x 4} \%+\frac{x 5}{\sum x 5} \%
$$

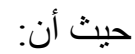

$$
\begin{aligned}
& \text { N = الوزن النسبي للمحور. } \\
& \text {. . . . x x } \\
& \text {. }
\end{aligned}
$$

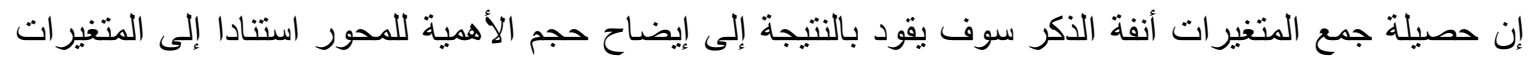

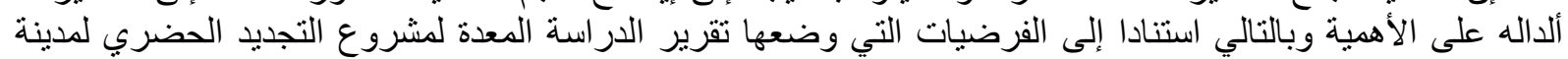

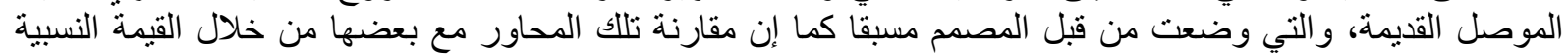
سوف يقود إلى معرفة التباين الحاصل بين المحاور من جهة وبين المحور المنتخب من خلال المسح الميداني من جهة

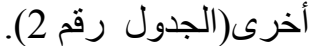

\begin{tabular}{|c|c|c|c|c|c|c|c|c|c|c|c|}
\hline الناتج & \multicolumn{2}{|c|}{ X5 } & \multicolumn{2}{|c|}{$\mathrm{X} 4$} & \multicolumn{2}{|c|}{$\mathrm{X3}$} & \multicolumn{2}{|c|}{$\mathrm{X} 2$} & \multicolumn{2}{|c|}{ X1 } & المحور \\
\hline & الوزن & القيمة & الوزن & القيمة & الوزن & القيمة & الوزن & القيمة & الوزن & القيمة & \\
\hline 143.93 & 16.74 & 1.320 & 46.15 & 6 & 36.36 & 4 & 14.07 & 0.047 & 30.61 & 15 & C1 \\
\hline 140.00 & $\overline{30.92}$ & 2.438 & 12.50 & 2 & $\overline{18.18}$ & 2 & $\overline{43.71}$ & 0.146 & 34.69 & 17 & $\overline{\mathrm{C} 2}$ \\
\hline 224.67 & 52.32 & 4.125 & 50.00 & 8 & 45.45 & 5 & 42.21 & 0.141 & 34.69 & 17 & $\overline{C p}$ \\
\hline & & & & & & & & & & & \\
\hline 33.13 & $\mathbf{0}$ & 0 & $\mathbf{0}$ & 0 & $\mathbf{0}$ & 0 & 19.41 & 0.066 & 13.72 & 7 & H1 \\
\hline 54.49 & 3.40 & 0.268 & 6.25 & 3 & 7.40 & 2 & 21.76 & 0.074 & 15.68 & 8 & $\mathrm{H} 2$ \\
\hline 113.69 & 49.82 & 3.917 & 12.5 & 6 & 14.81 & 4 & 20.88 & 0.071 & 15.68 & 8 & H3 \\
\hline 298.62 & 46.76 & 3.677 & 81.25 & 39 & 77.77 & 21 & 37.94 & 0.129 & 54.90 & 28 & Hp \\
\hline & & & 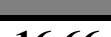 & & & & & & 190 & & \\
\hline$\frac{85.21}{50.68}$ & 30.19 & 4.211 & 16.66 & 7 & 16 & 4 & 9.46 & 0.086 & 12.90 & 12 & S1 \\
\hline$\frac{59.68}{52.58}$ & 7.46 & 1.041 & $\frac{14.28}{11.00}$ & $\frac{6}{5}$ & 16 & 4 & $\frac{10.12}{7.27}$ & 0.092 & $\frac{11.82}{1612}$ & $\frac{11}{15}$ & $\frac{S 2}{S 3}$ \\
\hline 51.41 & 15.91 & 2.219 & 4.761 & 2 & 8 & $\frac{\pi}{2}$ & 11.99 & 0.109 & 10.75 & 10 & S4 \\
\hline$\overline{58.09}$ & 9.68 & 1.351 & 7.142 & 3 & 8 & 2 & 21.45 & 0.195 & $\overline{11.82}$ & 11 & $\overline{\text { S5 }}$ \\
\hline 28.68 & 1.89 & 0.264 & 4.761 & 2 & 4 & 1 & 12.65 & 0.115 & 5.376 & 5 & S6 \\
\hline 34.24 & $\overline{4.13}$ & 0.576 & 7.142 & 3 & $\overline{8}$ & 2 & 10.67 & 0.097 & 4.301 & 4 & S7 \\
\hline 130.01 & 25.52 & 3.560 & 33.33 & 14 & 28 & 7 & 16.28 & 0.148 & 26.88 & 25 & Sp \\
\hline
\end{tabular}

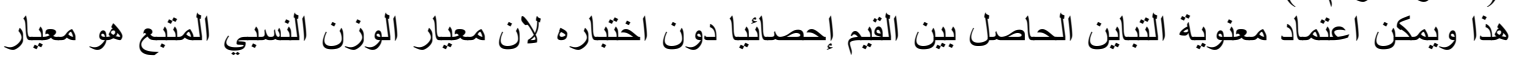

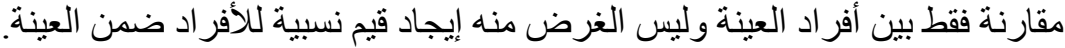

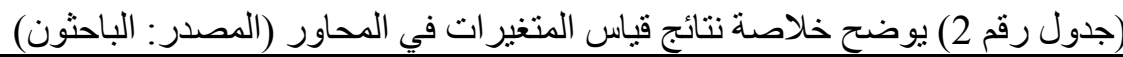

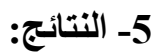

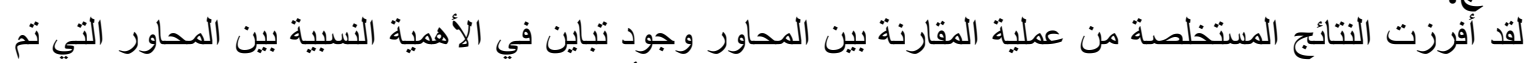
انتخابها في تقرير الدراسة عن تللك التي تم انتخابها بالمسح الميدة بن الني الني وكما يأني: 
1- فيما يتعلق بالمحور الثقافي جاءت الأهمية النسبية للمحور المنتخب بالمسح الميداني بأهمية نسبية بلغت (224.67)

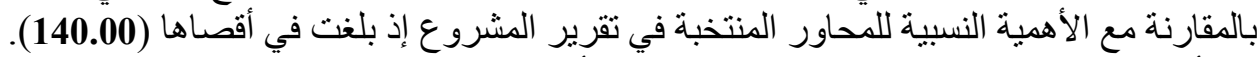

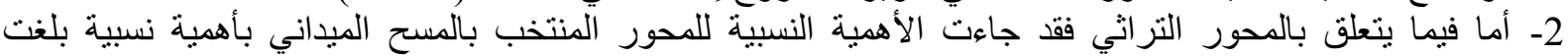

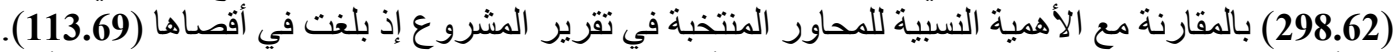

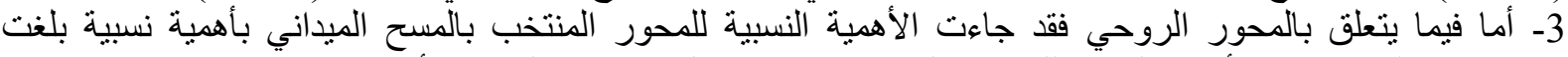

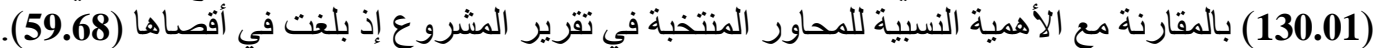

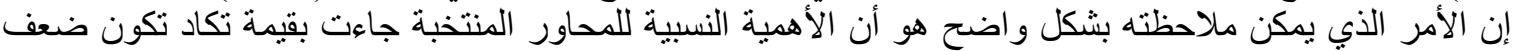
قيمتها لتلك المحاور المنتخبة في الدراسة.

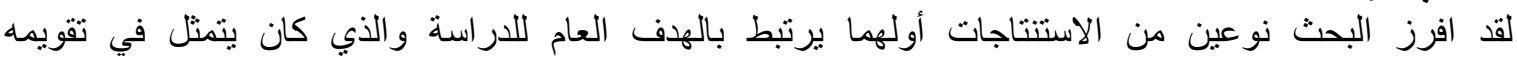

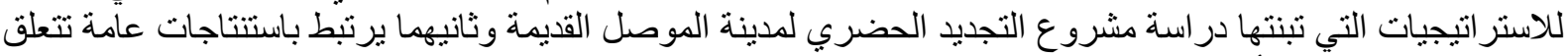
بموضوع البحث وكما يأني:

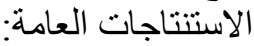

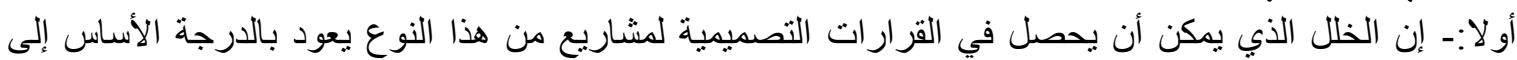

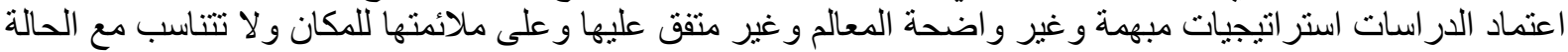

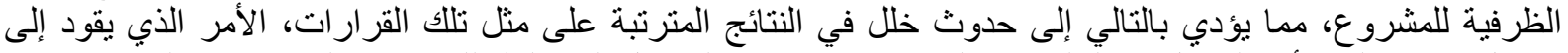

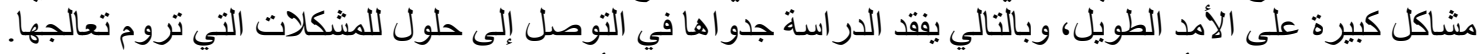

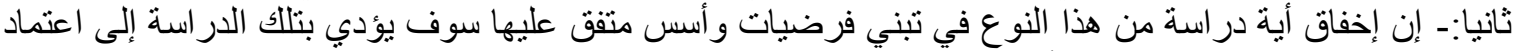

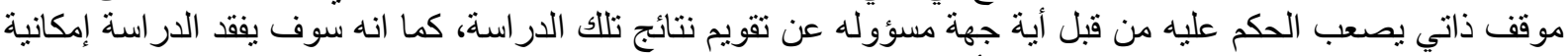
القياس او الحكم على قرار اتها وبالتالي يفقدها أهم ركيزة من ركائز مصدافئه فيتها.

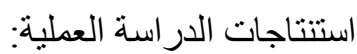

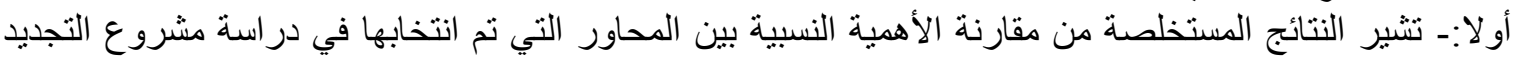

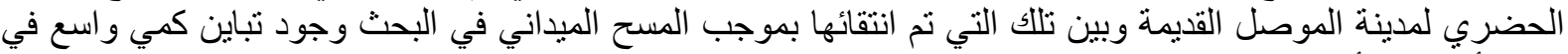

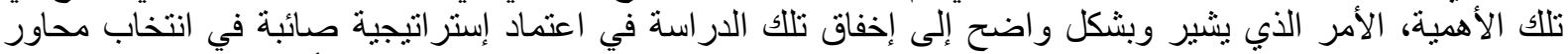

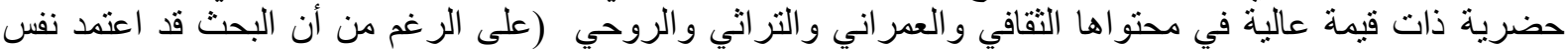

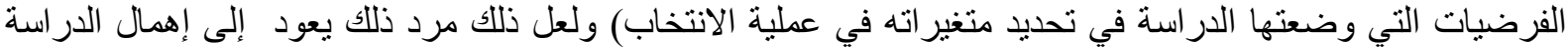

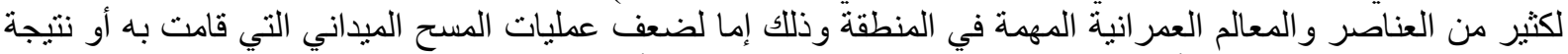

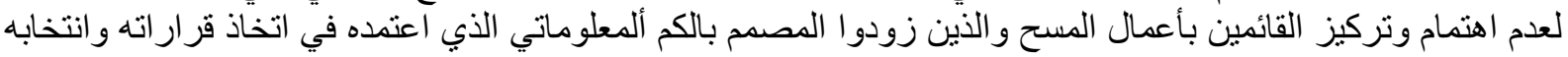

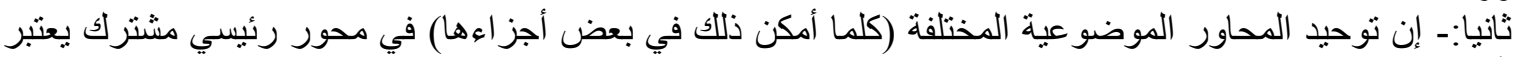

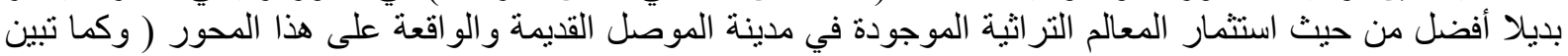

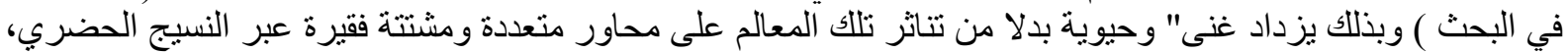

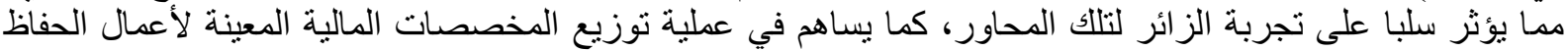

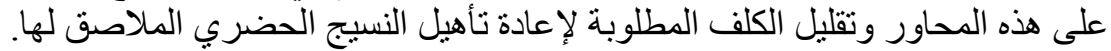

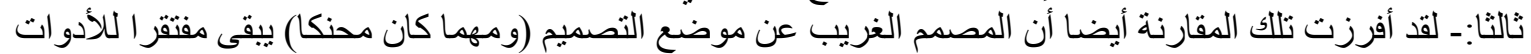

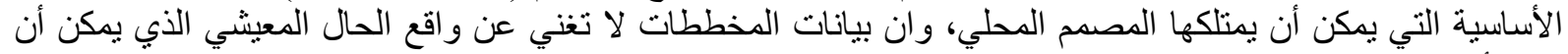

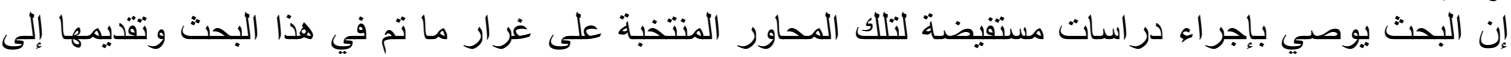

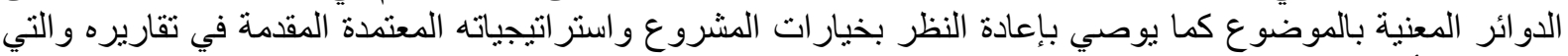

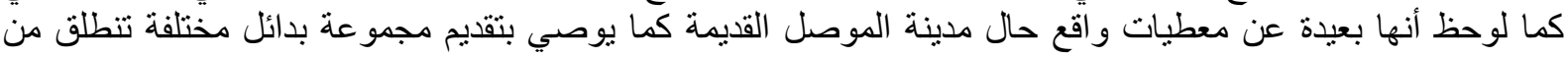
مقدمات مختلفة وذات معايير موضو عية تستند إلى معطيات واقع الحال حتى يتسنى للجهات المستقيدة المقارنة و الاختيار الموضو عي بين تلك البدائل . ومن نتائج البحث أعلاه يمكن التوصية بضرورة وجود هيئة استشارية لأعمال تجديد وصيانة نسيج المدينة القديمة تتضمن جميع الاختصاصات ذات الصلة بأعمال التجديد الحضري و الحفاظ على التراث المعماري على أن يكون معظم 
العاملين فيها من المتخصصين من أهل المدينة أو ممن عاثن فيها مع ضرورة مساهمة المجتمع المدني و أهالي المنطقة في الثيا

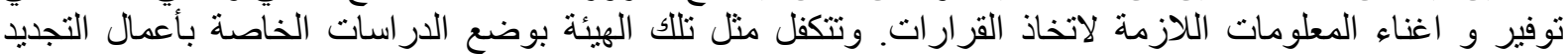

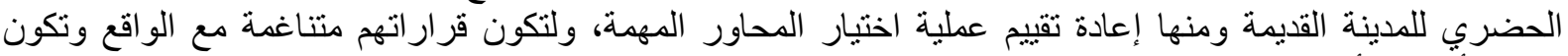

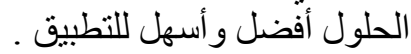

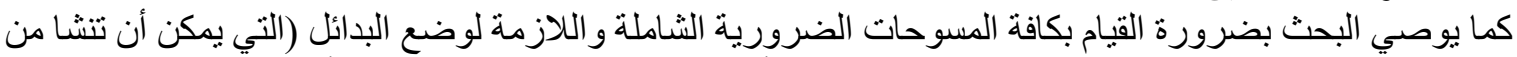

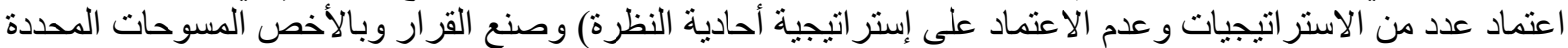

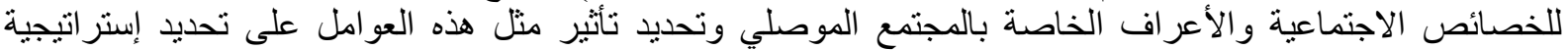
لانتخاب هذه المحاور، والتي لم يتضمنها التقرير الخاص بمشروع التجديد الحضري لمدينة الموصل القديمة.

ـ إبر اهيم، عامر نافع، التجديد الحضري في مركز مدينة الموصل، بحث غير منشور أطروحة ماجستير مقدمة إلى الجامعة التكنولوجية، بغداد 1989.

ـ الاسعدي، عصام محمود، صيانة الدور التراثية في العراق، بحث غير منشور أطروحة ماجستير مقدمة إلى جامعة بغداد، بغداد 1989.

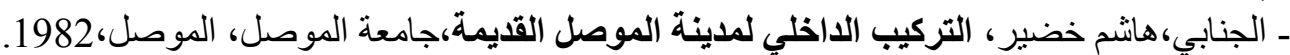

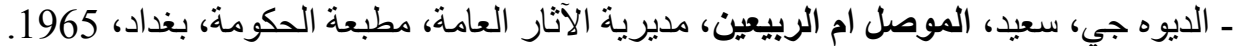

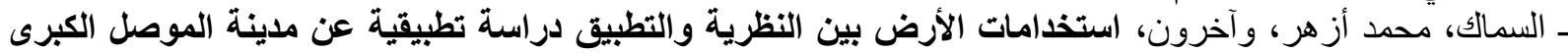

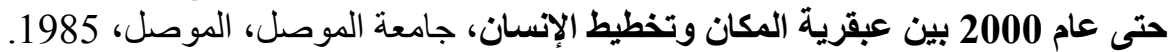

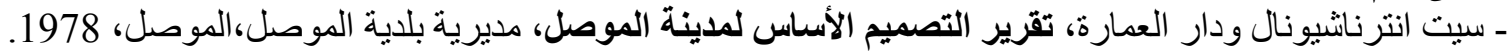

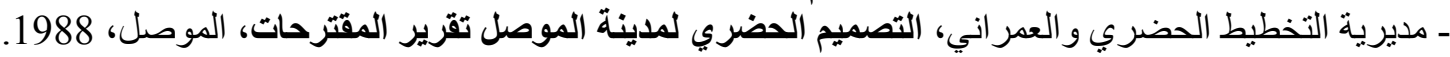

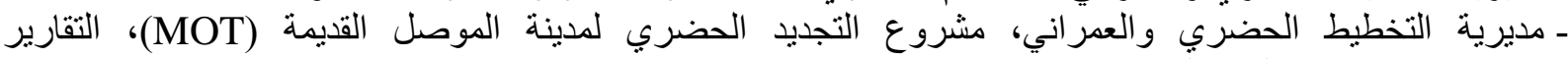

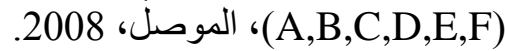
ـ الملا حويش، عقيل نوري، العمارة الحديثة في العراق دراسة مقارنة في هندسة العمارة والتخطبط، دار الثؤون العامة، بغداد 1988.

- Bently ,I., Responsive environments : amanual for designers, The Architectural Press Ltd., London,2001.

- David Seamon, The Life Of The Place: A Phenomenological Commentary On Bill Hillier's Theory Of Space Sytax, Nordisk Arkitekturforskning [Nordic Journal Of Architectural Research], 7, $1,1994$. pp: $35-48$

- Hillier B., \& Hanson, J.,. The Social Logic Of Space. Cambridge: Cambridge University Press, 1984.pp:28,96-97,108-109, 155.

- Hillier B., Space is the Machine: A Configurational Theory of Architecture, Cambridge University Press, Cambridge, $2^{\text {nd }}$ Ed., 2002. pp: 25,90-93.

- Laura Vaughan, The Spatial Syntax Of Urban Segregation. PROGRESS IN PLANNING, Vol. 67, Issue 4, 2007, DOI. pp: 207

- Lynch,K. ,The Image Of the City, The M.I.T Press, New York,1960.

- Saif-Ul Haq, Complex Architectural Settings: An Investigation Of Spatial And Cognitive Variables Through Wayfinding Behavior, Phd. Dissertation, Georgia Institute Of Technology, Bell \&Howell Information And Learning Company, 2001. Chapter IV, Space Syntax P.P 67-69,

- SCET International, MOSUL MASTER PLAN, Special area report, Mosul, 1978.

- Wiedenhoeft, R. CITIES FOR PEOPLE, PRACTICAL NEASURES FOR IMPROVING URBAN INVIRONMENT, van nostrand reinhold com. New York, 1981.

تم اجراء البحث في كلية ألهندسة = جامعة ألموصل 
No. 3

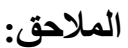

المحاور الروحية و التراثية و الثقافية كما حددها مشروع التجديد الحضري لمدينة الموصل القديمة :

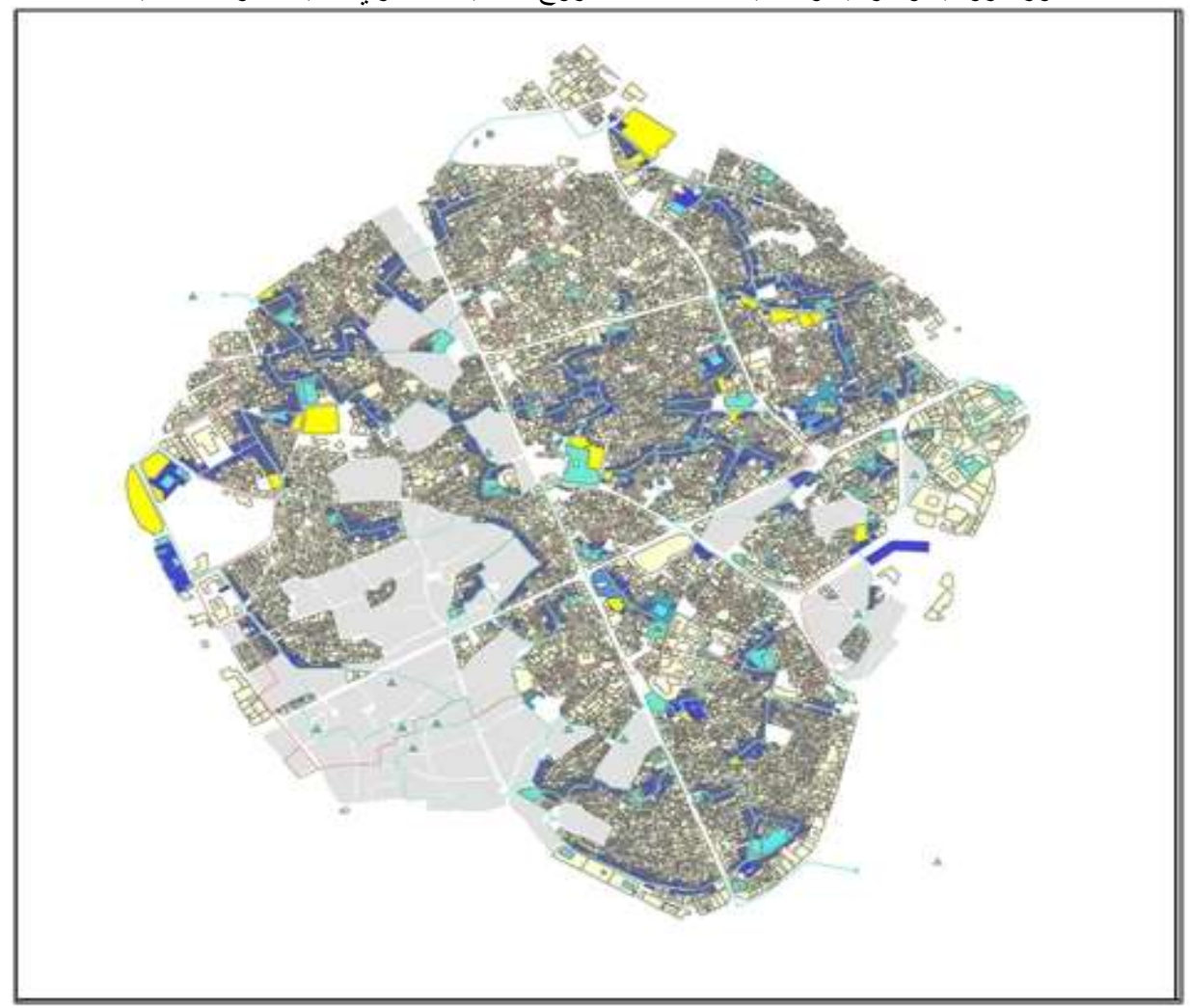

(ملحق رقم 1) المحاور الروحية (المصدر: مديرية التخطيط العمر اني تقرير 2008 E,F،ص، 128)

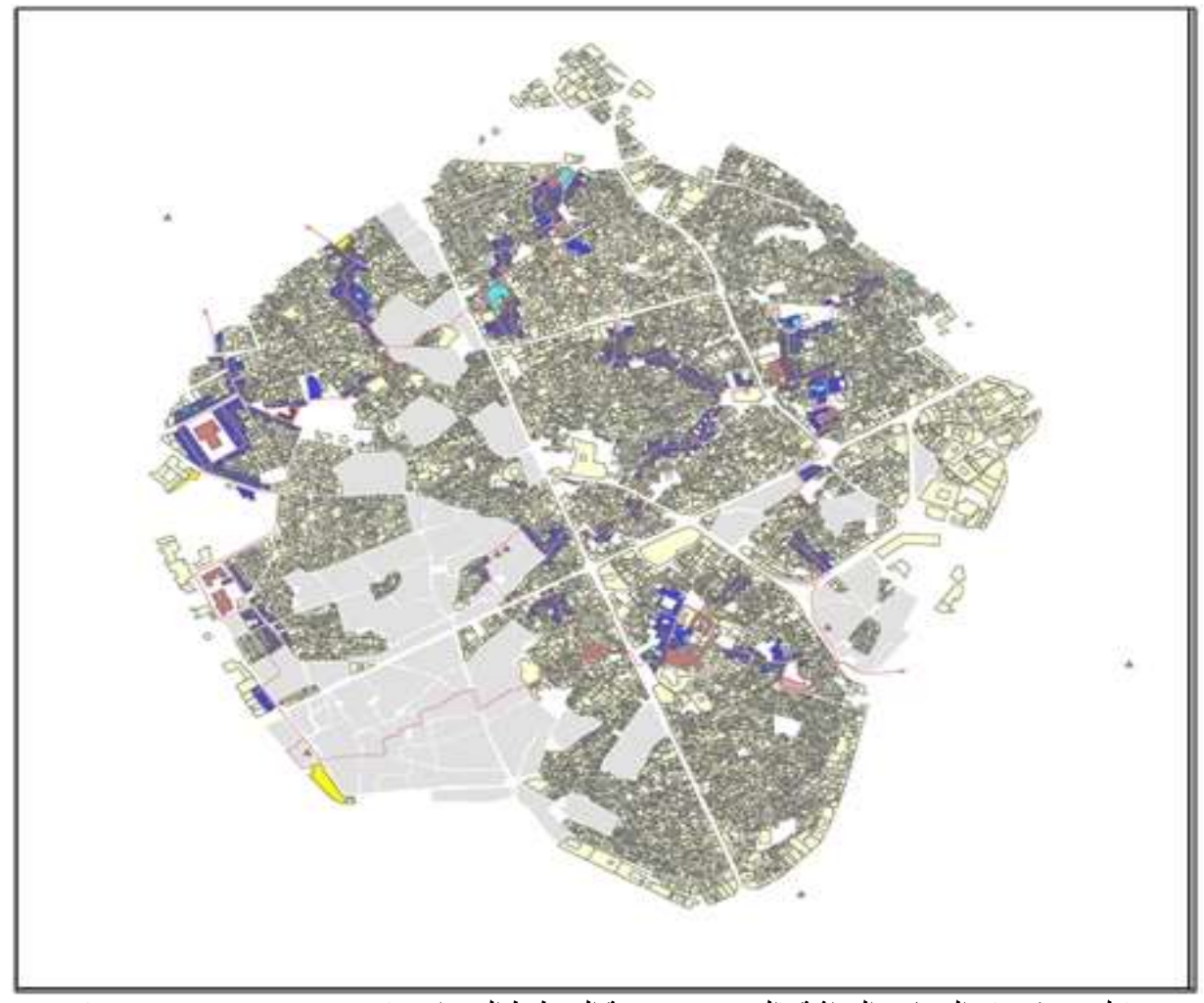

(ملحق رقم 2) المحاور التراثية (المصدر: مديرية التخطيط العمر اني تقرير 2008،ص، 128) 


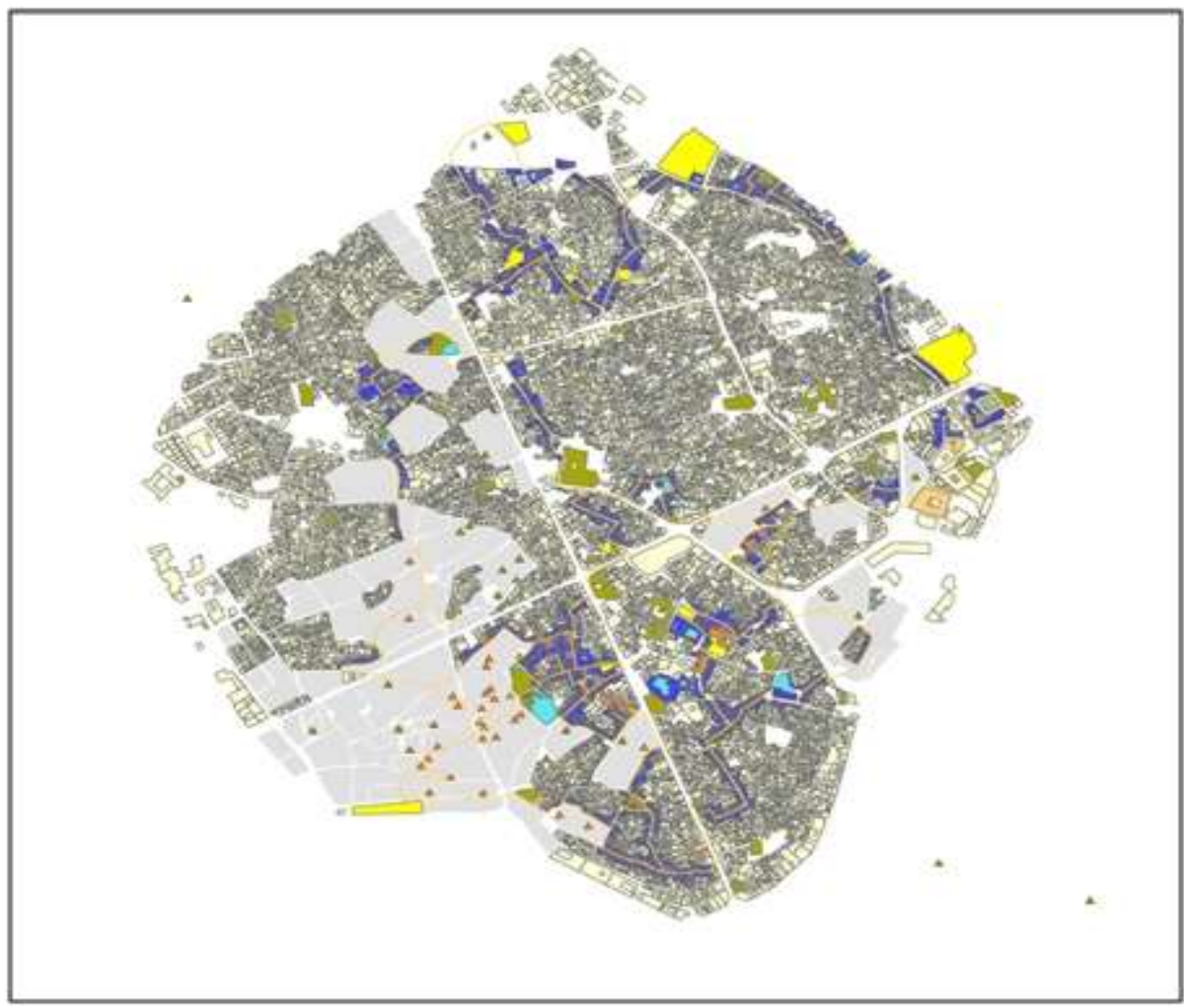

(ملحق رقم 3) الدحاور الثقافية (المصدر: مديرية النخطيط العمراني تقرير 2008،ص،، 128)

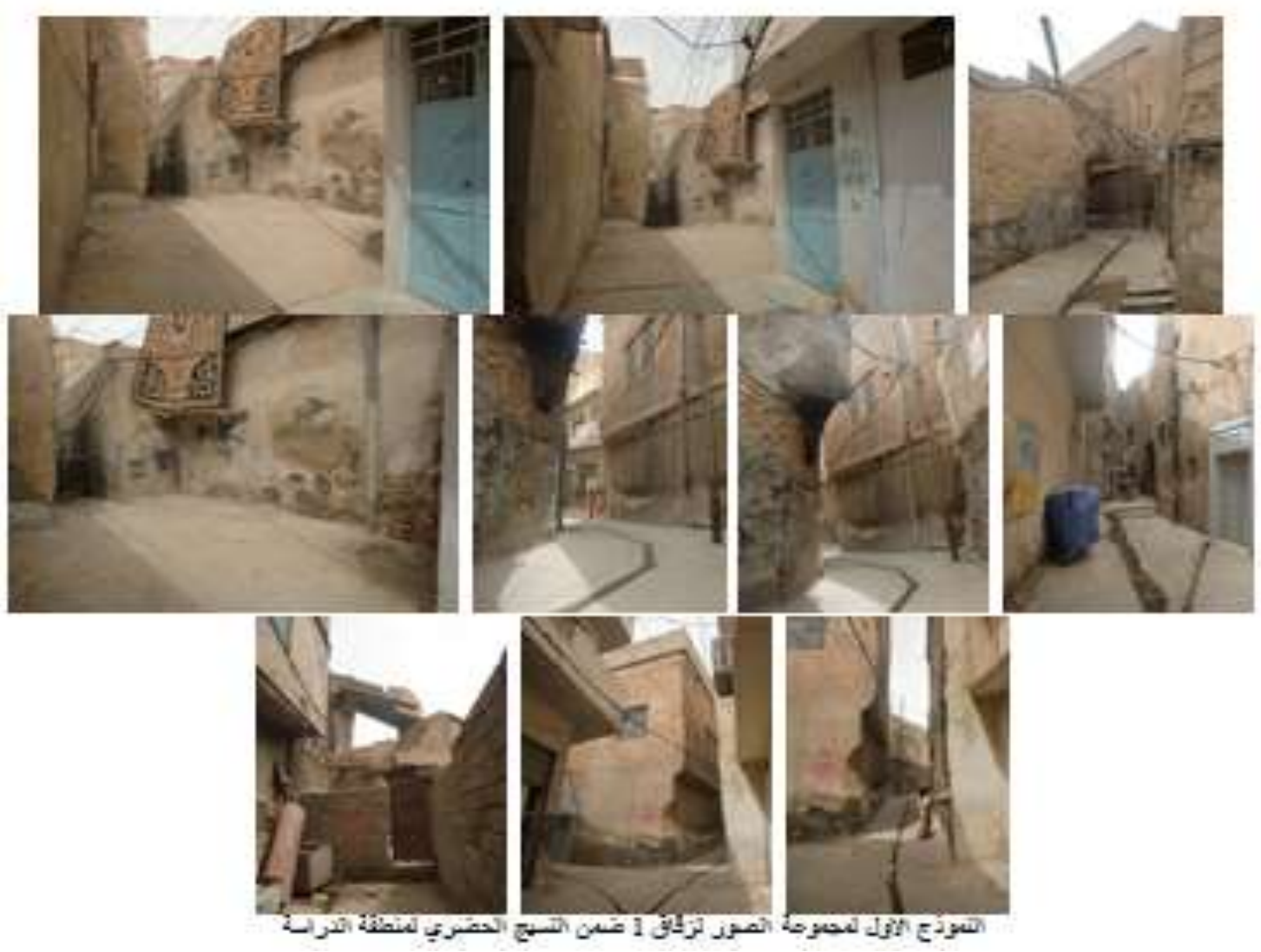


No. 3

April 2014
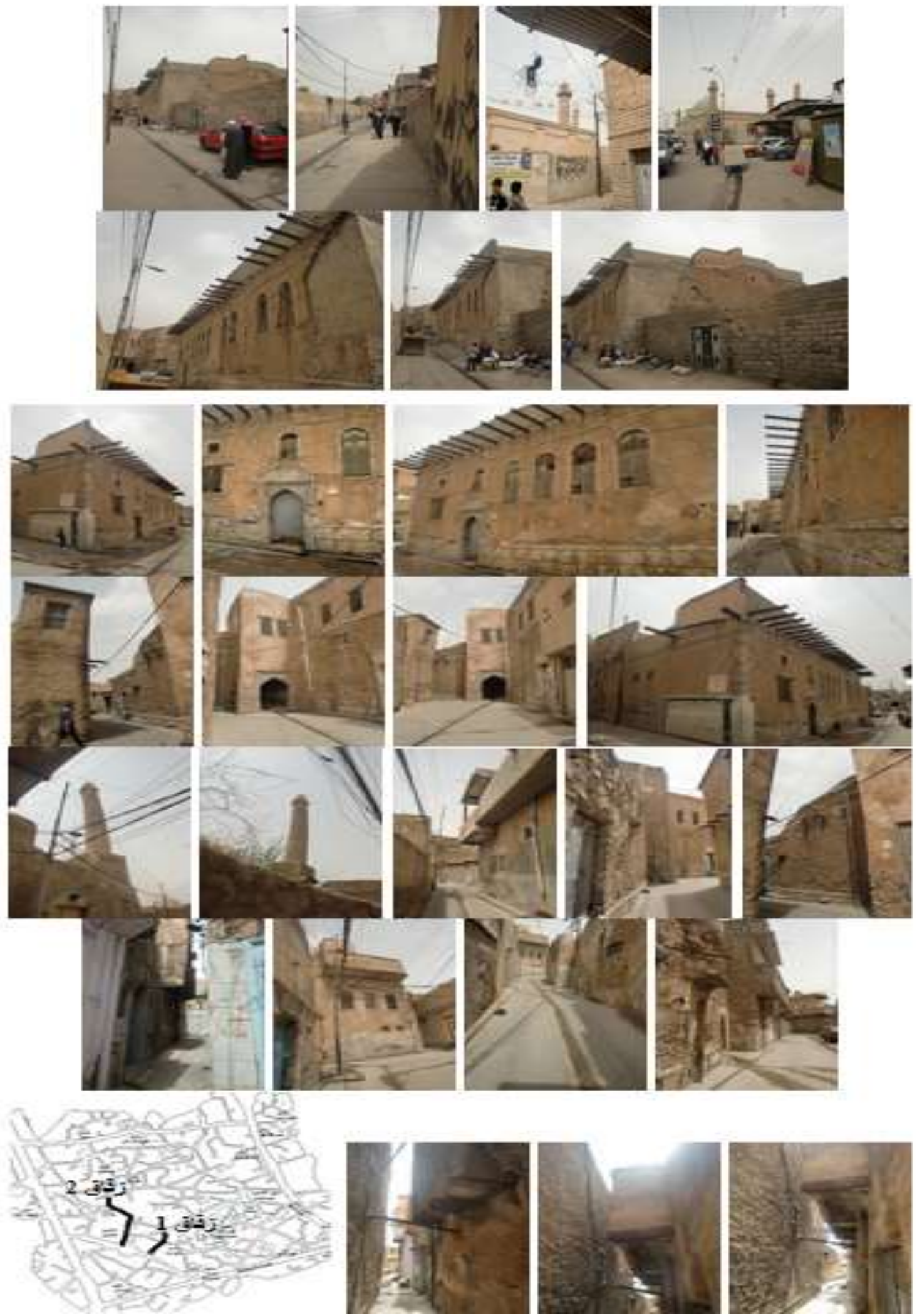

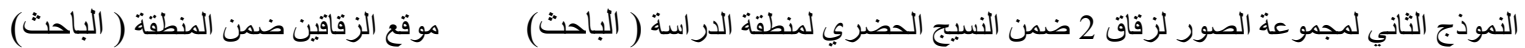
(ملحق رقم 4) نموذجين لعملية مسح الازقة من خلال عملية التصوير : بعض صور عمليات المسح الموقعي للمنطقة المنطقة قيد البرات

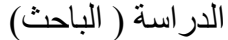

تمت عملية التصوير بطريقة متسلسلة للزقاق لغرض تسجيل تفاصيله المطلوبة قيد البحث 
(ملحق رقم 5) المسوحات الميدانية لو اقع حال المنطقة قيد الدراسة مع مخطط الابنية المهمة ونموذج من مسودات الدراسة الميدانية المانية

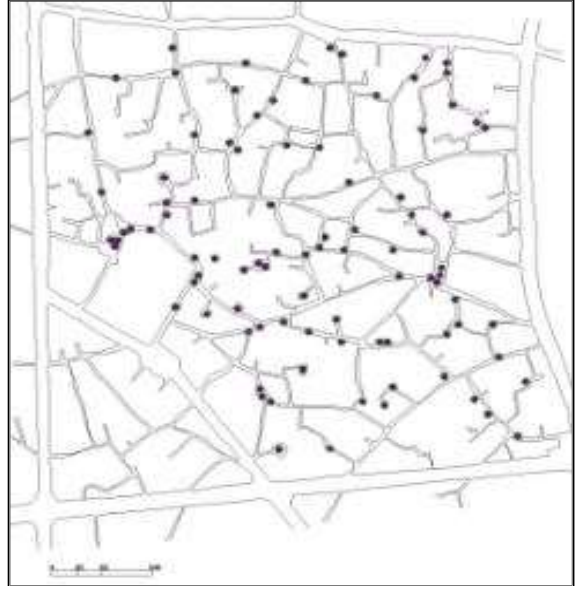

مو اقع الفضوات على المحاور ضمن منطقة الدراسة (الباحث)

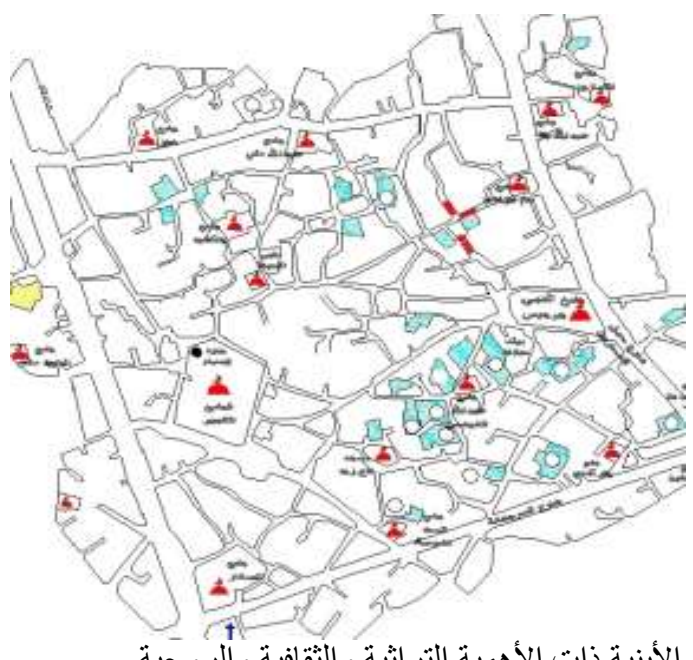

الأبنية ذات الأهمية التر اثية و الثقافية والروحية (المصدر: البيانات المعتمدة لمفتشية آثار وتراث نينوى)

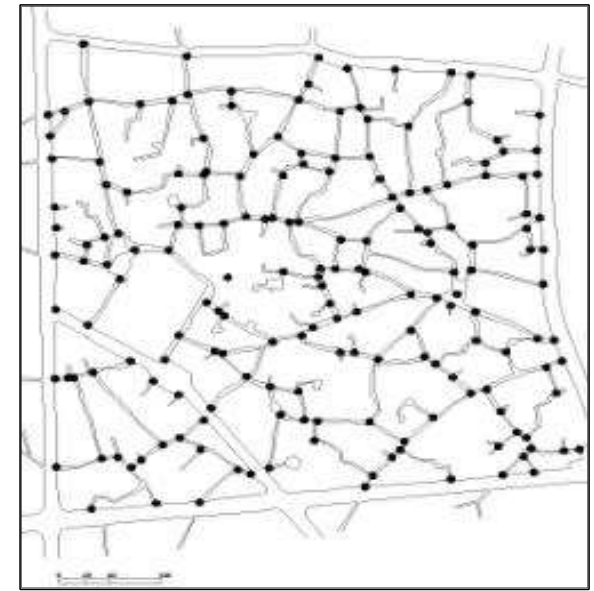

مو اقع الثقاطعات على المحاور ضمن منطقة الدراسة (الباحث)

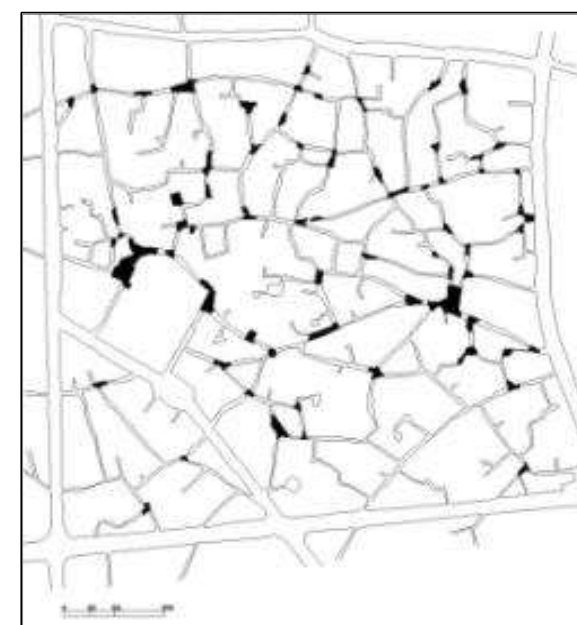

مساحة الفضوات على المحاور ضمن منطقة الدراسة (الباحث)

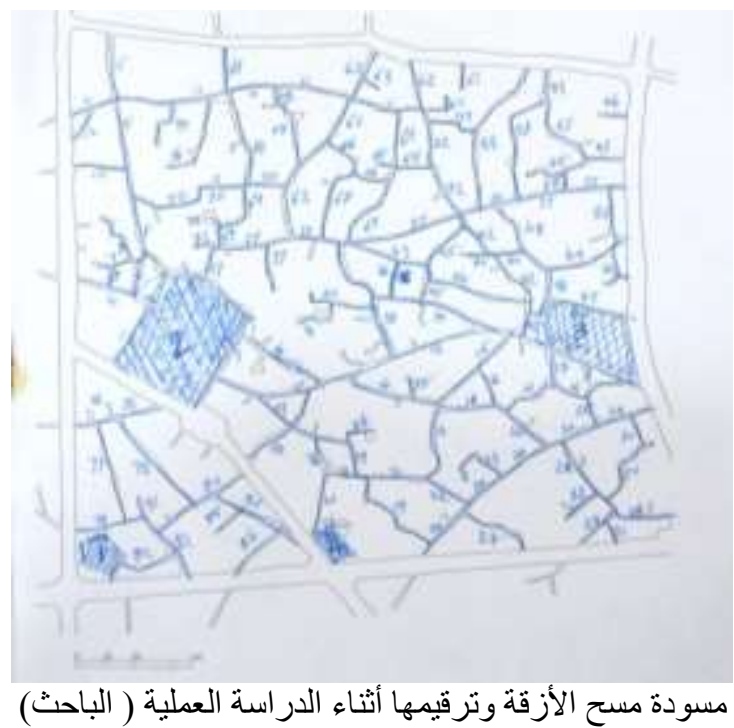

